San Jose State University

SJSU ScholarWorks

Master's Theses

Master's Theses and Graduate Research

1996

\title{
How occupational therapy perceptions and practices are being influenced by managed care
}

Cynthia Lynn Haut

San Jose State University

Follow this and additional works at: https://scholarworks.sjsu.edu/etd_theses

\section{Recommended Citation}

Haut, Cynthia Lynn, "How occupational therapy perceptions and practices are being influenced by managed care" (1996). Master's Theses. 1374.

DOI: https://doi.org/10.31979/etd.8jdz-fpnb

https://scholarworks.sjsu.edu/etd_theses/1374

This Thesis is brought to you for free and open access by the Master's Theses and Graduate Research at SJSU ScholarWorks. It has been accepted for inclusion in Master's Theses by an authorized administrator of SJSU ScholarWorks. For more information, please contact scholarworks@sjsu.edu. 


\section{INFORMATION TO USERS}

This manuscript has been reproduced from the microfilm master. UMI films the text directly from the original or copy submitted. Thus, some thesis and dissertation copies are in typewriter face, while others may be from any type of computer printer.

The quality of this reproduction is dependent upon the quality of the copy submitted. Broken or indistinct print, colored or poor quality illustrations and photographs, print bleedthrough, substandard margins, and improper alignment can adversely affect reproduction.

In the unlikely event that the author did not send UMI a complete manuscript and there are missing pages, these will be noted. Also, if unauthorized copyright material had to be removed, a note will indicate the deletion.

Oversize materials (e.g., maps, drawings, charts) are reproduced by sectioning the original, beginning at the upper left-hand corner and continuing from left to right in equal sections with small overlaps. Each original is also photographed in one exposure and is included in reduced form at the back of the book.

Photographs included in the original manuscript have been reproduced xerographically in this copy. Higher quality 6" 19 " black and white photographic prints are available for any photographs or illustrations appearing in this copy for an additional charge. Contact UMI directly to order.

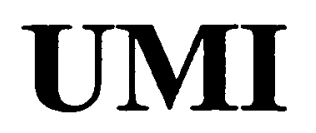

A Bell \& Howell Information Company 



\title{
HOW OCCUPATIONAL THERAPY PERCEPTIONS AND PRACTICES ARE BEING INFLUENCED BY MANAGED CARE
}

\author{
A Thesis \\ Presented to \\ The Faculty of the Department of Occupational Therapy \\ San Jose State University \\ In Partial Fulfillment \\ of the Requirements for the Degree \\ Master of Science \\ by \\ Cynthia Lynn Haut \\ December 1996
}


UMI Number: 1382578

UMI Microform 1382578

Copyright 1997, by UMI Company. All rights reserved.

This microform edition is protected against unauthorized copying under Title 17, United States Code.

\section{UMI}

300 North Zeeb Road

Ann Arbor, MI 48103 
APPROVED FOR THE DEPARTMENT OF OCCUPATIONAL THERAPY

Karen Diasio Serrett, Ph.D., OTR, FAOTA

Horew Aiveci terret

Alice Kibele, M.S., OTR

Rivie Kebeli

Janet Jabri, OTR, M.B.A., FAOTA

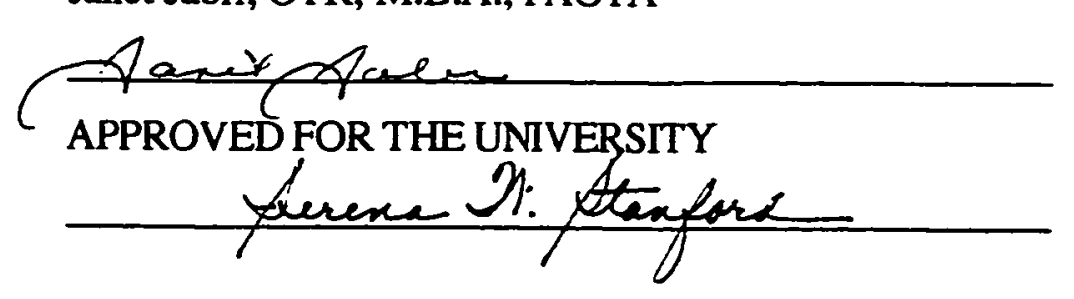


(C) 1996

Cynthia Lynn Haut

ALL RIGHTS RESERVED 


\section{Abstract \\ HOW OCCUPATIONAL THERAPY \\ PERCEPTIONS AND PRACTICES \\ ARE BEING INFLUENCED BY \\ MANAGED CARE \\ by Cynthia Lynn Haut}

The purpose of this research was to assess the perceptions of occupational therapy directors regarding the impact of managed care on occupational therapy. The perceptions were investigated in ways that provided a clear picture of the following: (1) the changes in occupational therapy services delivery, (2) the attitudes that occupational therapy managers have about those changes in the workplace, and (3) the education that occupational therapists need to best respond to changes in their roles and environment.

Findings revealed that reorganization due to managed care has promoted increases in patient education, case management, cost containment, continuous quality improvement and the use of aides in treatment settings. Occupational therapy managers perceptions of those changes show a lack of system and process quality. Even as provider staff increase patient satisfaction efforts, patient care has become untimely due to reimbursement procedures and limited by poor understanding of the occupational therapist role and distrust of their professional expertise. Education is recommended that expands our role in the community, proves our value through functional outcomes, lays a common ground of understanding the change process, and builds a positive reimburser/provider relationship. 


\section{Acknowledgements}

This research was made possible through the support, energy and dedication of hundreds of people who are concerned about the current status of health care. Each offered personal and professional expertise in hopes that these research findings would positively impact future health care reform.

This research would not have been possible without the financial endowments of two fine educational entities. The California State University System initiated this process through an award to develop this research. The San Jose State University Foundation generously provided grant funding to perform in-depth analyses of the results and to present those research findings at both state and national level conferences.

The quality of this research is a reflection of the top-notch advisors who offered their precious time and knowledge throughout its development and implementation. My deepest thanks goes to Karen Diasio Serrett, Ph.D., OTR, FAOTA. Her visionary thinking, personal thirst for knowledge, enthusiasm for discovery made this thesis process a joyous, consciousness-expanding experience. My thesis committee members, Jan Jabri, OTR, M.B.A. and Alice Kibele, M.S. OTR were extremely supportive and accessible throughout the process. Both readers made timely recommendations that focused the research on crucial concerns and reflected true personal expertise. Fran Stancavage, Senior Research Associate, and Dr. John Olsen, Senior Research Associate, of American International Research both took precious time from their schedules for questionnaire design methodology consultation.

Finally, I would like to acknowledge all of the occupational therapists who took the time to respond to the questionnaire. Their efforts showed a true dedication to patient well being and a passion for professional excellence. 
Table of Contents

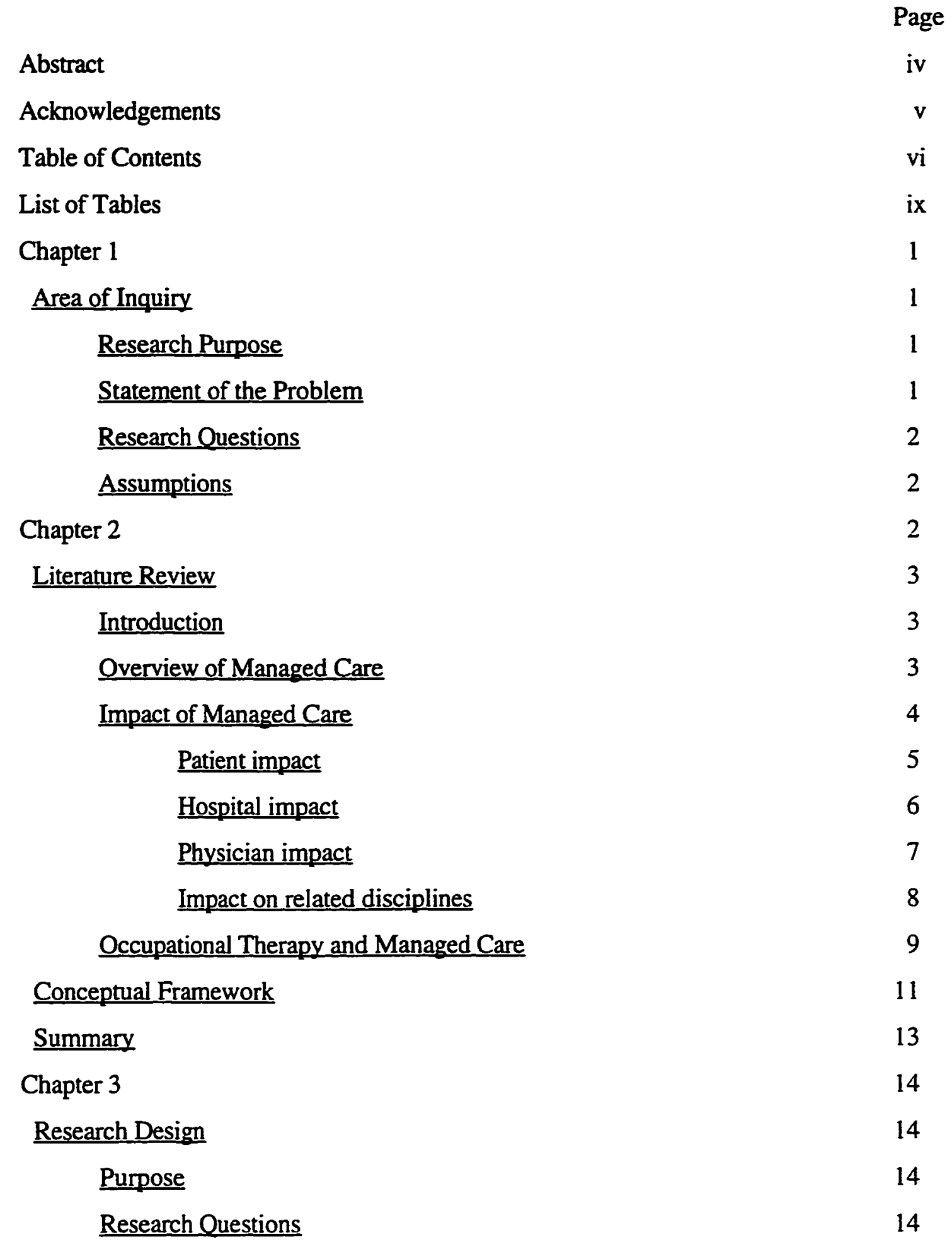


Research Design Development $\quad 14$

Sample $\quad 15$

$\begin{array}{ll}\text { Research Methodology } & 15\end{array}$

Instrumentation and Procedures $\quad 15$

$\begin{array}{ll}\text { Data Collection and Analysis } & 16\end{array}$

$\begin{array}{ll}\text { Resources } & 17\end{array}$

Limitations 17

$\begin{array}{ll}\text { Chapter } 4 & 18\end{array}$

Data 18

$\begin{array}{ll}\text { Introduction } & 18\end{array}$

$\begin{array}{ll}\text { Demographics } & 18\end{array}$

$\begin{array}{lr}\text { Organizational Demographic Characteristics } & 18\end{array}$

Personal-Performance Demographic Characteristics 22

Geographical States $\quad 22$

Research Findings $\quad 22$

Question One $\quad 23$

Question Two $\quad 23$

Question Three $\quad 29$

Question Four 31

Question Five $\quad 36$

$\begin{array}{ll}\text { Chapter } 5 & 40\end{array}$

$\begin{array}{ll}\text { Discussion } & 40\end{array}$

Organizational Change and Managed Care Influence $\quad 40$

Comparisons Across Geographical Areas $\quad 40$

Clinical Practice Changes $\quad 42$

Managed Care Change Perceptions 44

Managers' Recommendations for Further Education 46

$\begin{array}{ll}\text { Implications } & 47\end{array}$ 
Recommendations for further research

References

$\begin{array}{ll}\text { Appendix A } & 58\end{array}$

Definitions $\quad 58$

$\begin{array}{lr}\text { Appendix B } & 59\end{array}$

Consenting Cover Letter for Participants $\quad 60$

Appendix C 61

$\begin{array}{ll}\text { Questionnaire } & 62\end{array}$

Qualitative Questionnaire Supplement $\quad 66$ 


\section{List of Tables}

Pages

Table 1: Organizational Demographic Characteristics of Respondents 19

Table 2: Personal-Performance Demographic Characteristics of Respondents $\quad 20$

Table 3: Geographical States Represented by Respondents 21

Table 4: Influence of Managed Care Contracts on Organizational Changes 24

Table 5: Occupational Therapy Staffing Mix Changes in Last Two Years 25

Table 6: Organizational Status in Relation to Managed Care 27

Table 7: Length of Time Each Practice Setting Has Had Managed Care Contracts 28

Table 8: Clinical Practices Which Have Altered the Most in the Last Two Years 31

Table 9: Workplace Perceptions Strongly Held By Occupational Therapy Managers $32-36$

Table 10: Need for Occupational Therapist Education 37-39 


\section{Chapter 1 \\ Area of Inquiry}

\section{Research Purpose}

The purpose of this research is to assess the perceptions of occupational therapy directors regarding the impact of managed care on occupational therapy. The perceptions will be investigated in ways that will provide a clear picture of the following: (1) the changes in occupational therapy services delivery, (2) the attitudes that occupational therapy managers have about those changes in the workplace, and (3) the education that occupational therapists need to best respond to changes in their roles and environment. A clear understanding of the current national position of occupational therapy leaders is needed for the profession of occupational therapy to collectively position itself proactively within the changing health care environment.

\section{Statement of the Problem}

The United States is engaged in a major debate over the structure of its health care system. Managed care plays an essential role in many health care reform proposals currently under consideration (Miller \& Luft, 1994). Managed care is a system of health care provision that addresses patient needs through a spectrum of alliances in order to control the cost of, access to and quality of health care (Todd, 1993). As these alliances form and develop, health care professionals will see shifts in the scope, nature and quality of the work they provide (Thiers, 1994). The environment of cost containment leaves occupational therapists "caught between the pressures of patients' demands for quality care and the drive to control costs," which "creates professional and emotional conflict" (Foto, 1988a, p. 564). Occupational therapists need to understand managed care and its evolution within the health care industry if they are to collaborate with managed care entities and market their skills (Smith \& Elberth, 1993). Historically, the effect of the reimbursement changes on occupational therapy has translated into a change in the profession's definition, treatment modes, management, ethics, and political activity (Howard, 1991). Burke and Cassidy (1991) examined the disparity between the existing humanistic valued philosophies 
of occupational therapy and the recently imposed reimbursement-driven practices. They identified new treatment models, responsibilities and ethical dilemmas as affecting the role definitions of occupational therapists. Clearly, the occupational therapy profession needs to face the occupational challenge of assessing these changes and proactively adapting the profession's response to managed care in ways that will maintain the profession's integrity, increase awareness of the need for occupational therapy and assure its inclusion within the managed care environment.

\section{Research Questions}

1. To what degree do occupational therapy managers perceive organizational restructuring changes to be influenced by managed care demands?

2. How do occupational therapy staffing mix changes compare in California, Illinois and New York?

3. Which clinical practice changes are identified by occupational therapy managers as altering the most dramatically in the last two years?

4. Which perceptions of managed care change are the most strongly held by occupational therapy managers?

5. What educational recommendations do occupational therapy managers make for health care professionals to help them successfully manage their careers within this changing environment?

\section{Assumptions}

The researcher held three main assumptions while doing this study. Those assumptions include: (1) those surveyed understood the terminology used in the questionnaire, including the use of managed care and management terms, (2) not all surveyed will have been impacted by managed care to the same extent as others, and (3) level of knowledge and contribution will vary with facility, area of practice and geographic location. 


\section{Chapter 2}

\section{Literature Review}

\section{Introduction}

Although little scholarly research has been formulated on the topic of managed care, the amount of current literature discussing this health care provision is overwhelming. Managed care and managed competition are phrases that create confusion and uncertainty in both meaning and scope. Although many people are beginning to be affected by its long reach, few clearly understand just what managed care offers or how it works. This review will (1) present a general overview of managed care, (2) consider its impact from the perspective of the patient, hospital, and related disciplines, (3) review literature that has investigated the relationship of occupational therapy and managed care, and (4) discuss the conceptual framework on which this research is based.

\section{Overview of Managed Care}

Managed care is a system of health care provision that addresses patient needs through a spectrum of alliances in order to control the cost of, access to and quality of health care (Todd, 1993). The organizational models of managed care companies will vary according to how fees are paid, whether the patients may seek care outside the network, and who manages the daily clinical operations. The single most important feature that distinguishes a managed care model from a fee for service plan is utilization management (Miller \& Luft, 1994). Utilization management involves the review and evaluation of each patient's treatment in terms of medical necessity, appropriate setting, utilization frequency, and resource management (Burcham, 1994). The goal of utilization review is to contain costs by having the treatments justified according to appropriateness, efficiency, and effectiveness (Burcham, 1994).

Utilization management initiatives have contributed to massive system reorganization, work process reengineering and new role definitions in health care. The quest to define those terms and incorporate them into the current health care infrastructure has changed the philosophical base of social planning for health care (Ellek, 1990). The 
medical ethics principle of utility states that "we should act in such a way as to bring about the greatest benefit and the least harm" (Bailey \& Schwartzberg, 1995, p. 6). Legislators in the 1960s (Ellek, 1990) defined this ethic as applying to each person as a social good through the health policies aimed at gaining health care access to a greater proportion of the population. With the growth of technology, services, the eligible population, and subsequently health care costs, the right to health care is now being viewed as an economic good rather than a social good (Marszalek-Gaucher \& Coffey, 1990). This has created pressure to use managed care to limit an individual from achieving the greatest benefit in favor of balancing the needs of the entire society.

Support of managed care comes from several sectors. Advocates for less government see managed care as a solution to preserve the private insurance industry and private sector management of the U.S. health care system (Hall, 1992). Critics of managed care caution that the profit motive of managed care organizations can loom as a threat to the patient's best interests (Reinhardt, 1986).

Managed care providers are credited with changing the measures of success to include quality assurance and outcomes research in an attempt to justify their judgments about the level of benefits provided (Ellek, 1995). Organizational change efforts like the application of total quality management to improve client care and minimize extraneous operational costs require a change in the value system of the institution. Empowering people with crucial decision-making responsibility at all levels and widening the span of control are the keys to successful implementation of these quality improvement changes (Koumoutzis, 1994). This conflicts with managed care's utilization management goal of narrowing the span of control by forcing clinical treatment decisions through an outside review process (Burcham, 1994).

\section{Impact of Managed Care}

The impact of managed care has touched every player in the health care arena from the patients to the hospitals to the clinicians. Each group of stakeholders has been presented with different challenges and opportunities. 
Patient impact. A meta-analysis of managed care plan performance (Miller \& Lufts, 1994) revealed clear impact patterns of managed care on patient care. The analysis examined quasi-experimental studies dated 1980 or later, with private insurance or Medicare plan enrollees and a comparison group. A reasonable attempt at statistical adjustment was made for non-comparable managed care and indemnity insurance enrollees. Compared with indemnity plans (traditional insurance), health maintenance organizations had lower hospital admission rates, shorter hospital stays, the same or more physician office visits per enrollee, less use of expensive tests and procedures, and greater use of preventative services. The data also reported mixed reviews of patient satisfaction. For HMO enrollees, the perceived quality of care and physician interaction was lower than feefor-service enrollees and while HMO enrollees expressed a higher satisfaction over costs, there was a lower satisfaction with services (Miller \& Lufts, 1994). This analysis did not examine the treatment efficacy or patient outcomes. The design of the meta-analysis was limited by too few observations of plan differences, a selection bias of only successful HMO study participation and too few of the studies controlled for benefit differences, outof-pocket cost savings, local market characteristics or state regulations. These factors make it difficult to generalize from the results of the studies analyzed in the meta-analysis. While the access to and cost of services were comprehensively examined, the question remains as to the whether the services delivered were of sufficient quality to meet the patient's needs.

Many patients who require medical attention have difficulty entering the continuum of care at the appropriate level (Salcido, 1995). These difficulties may arise due to limited financial status, family and transportation difficulties or living in regions that lack a medical facility equipped to handle their needs.

Other concerns by those patients involved in managed care include poor access to services, few stable patient-doctor relationships, uncertainty about quality, and uneven client-provider satisfaction. Fisher (1994) provided an overview of state government motivation to develop managed care arrangements under Medicaid programs for the poor and found that patients under managed care were limited in their choice of provider, were 
less likely to switch health care providers if care quality was poor, and found difficulty being reimbursed for special problems like alcohol abuse or specialized care for crack babies.

Within the mental health field, Wooley (1993) expressed dismay over managed care's denial of benefits for patients who require more than 20 sessions and by definition need long-term therapy. In her opinion, the sickest patients, who need the most care, are being selectively denied.

Miller (1994) documents a positive impact for patients in the delivery of addiction services. More comprehensive evaluations and treatment planning are being achieved in companies characterized by fairly administered managed care, a willingness to settle for reasonable profits, an interest in delivering a quality product, and maintenance of a patient wellness philosophy.

There is an abundance of articles which highlight deficiencies found in managed care service quality and access. In light of this, it is clear that closer attention should be paid to patient education and satisfaction as part of the managed care formula.

Hospital impact. Health care providers have responded to the access, quality and cost of managed care provisions through the implementation of several initiatives. Many hospitals that are looking for ways to improve patient access are buying primary care medical practices, merging with other hospitals, or setting up their own HMOs (Anders \& Stout, 1994). These alliances strategically focus on building strength both horizontally and vertically in the market in order to secure lucrative managed care contracts (Fowler \& Gill, 1994). When an HMO is looking to contract for ancillary services, it considers how diversified the hospital is, whether it has multiple sites, the number of specialties offered, and its certifications (Egan, 1992).

Many health care entities are addressing quality through the development of Continuous Quality Improvement (CQI) programs which defines quality as meeting the needs of the patient and focuses on work processes and team building (Higgins, 1992). CQI programs as well as critical pathways are being developed to improve the quality of its 
services for certain rehabilitation diagnoses (Sullivan, 1995). Total quality management provides the grounding in philosophy and method for clinical pathways treatment (Spicer, 1992).

To be cost competitive in a managed care environment, administrators will need to maintain good information systems for the collection and dissemination of data on organizational efficiencies and quality of care (Wilson, 1993). Those who will thrive best in the outcomes-oriented health care culture will add key elements often missed in basic data bases (Wilkerson, 1995). These elements include: patient comorbidities, severity of illness for risk adjustment, pre- and post- rehabilitation social and physical environment, intervention and process data described in terms of outcome goals, and finally, cost (as opposed to charges) at the patient level of services.

Coile (1994) identified five transitional stages that hospital markets go through as they develop the integrated delivery systems expected by managed care. Each stage is hallmarked by popular transition strategies. Stage one markets have little managed care experience and are focused on forming alliances. These hospitals should be cautious in their rush to integration and should examine selection criteria and financial commitments that the integration opportunities offer. In stage two, hospitals recognize managed care's arrival and are preparing through the development of staff and capital. Managed care penetration in stage three reveals such strategies as reducing staff levels, development of clinical pathways and capitation of physician groups. Stage 4 markets, which are predominantly on the West Coast, are marked by actions such as clinical consolidation on a regional basis and pruning of contracts and costs. Post reform or stage five markets such as Albuquerque show providers merging with payers, focusing on prevention. HMOs and providers in stage five should expect their performance data to be made public.

Physician impact. Within the managed care environment, doctors have often been established in service gatekeeper roles in response to the need to contain costs. Each doctor who takes care of patients enrolled in a managed care plan receives printouts which identify how much he or she is spending on patients and how often they refer their patients 
to specialists in comparison with other doctors in the network (Alvarado, 1995).

Compensation and often continued coverage under the managed care contract are dependent upon the efficacy outcome of their printout report cards (Alvarado, 1995). While this move may seem necessary to managed care administrators attempting to curtail unnecessary expenditures, it brings cost issues directly into the doctor-patient relationship and can create potential ethical dilemmas with Hippocratic oath priorities (Sharfstein, 1994).

Impact on related disciplines. Role definitions across health care disciplines are being rethought in an attempt to prove value. Wilson (1993), views managed care as an opportunity for nurses to demonstrate how effective they really are in the optimization of cost and patient care quality outcomes within managed competition. She recommends that the nurse practitioners direct their efforts toward improved data collection, and proof of patient outcomes and be more proactive in the decision-making process. This is a recurring theme equally applicable to all disciplines in health care. The initiative of proving value through research of performance outcomes and voicing those values at contract time seem mandatory in the managed care environment.

Developing the business acumen involved in packaging and marketing services was discussed by Madden and Ponte (1994) in their recommendations to advanced practice nurses. The advanced practitioner was directed to decide whether their skills, expertise, and strengths fit with the network's character and expectations. Within managed care, this profile analysis is critical to the positioning needed to play a leading role in care improvement teams and maintain the salaries currently enjoyed by nurse practitioners.

Several authors (Clifton \& Tecklin, 1995; Singer, 1994; Wilkerson, 1995) discuss the importance of documentation changes to enhance the value of physical therapy in a managed care setting. Each discussed the importance of translating the therapy documentation into illustrations of the patient's true functional status. Physical therapists must be able to prove that they have improved the patient's lifestyle, integrated the patient back into a work setting or returned the patient to activity through therapy in order to receive reimbursement. Clifton and Tecklin (1995) addressed the scrutiny physical therapy 
has received under managed care. Many utilization review programs consider physical therapy as high in cost or highly discretionary. This poor reputation has been enhanced by a report from the Office of the Inspector General which found that almost 4 out of 5 cases reimbursed in physicians' offices do not represent true physical therapy services (Clifton \& Tecklin, 1995).

\section{Occupational Therapy and Managed Care}

Although there is much discussion in occupational therapy literature about managed care, its negative potential for patients, and strategies to weather managed care, little has been formally researched to investigate what impacts managed care has had on occupational therapy, what strategies occupational therapists are using to cope with these impacts, or how effective those strategies are.

Under the managed care umbrella, reorganization of hierarchical structures, patient care programs, resources restrictions and demands for outcome data are causing changes in the patient care routines of rehabilitation professions. Cliches like "doing more with less" are becoming a reality as occupational therapy departments are being asked to extend their services and productivity without adding positions. The addition of more nonprofessional staff such as OT aides and the increased use of groups are being used to streamline the operating budgets (Thiers,1994). Increased workload and changes requested by managed care have produced a need to shift the structure and work processes of the rehabilitation team. The Pew Health Profession's Commission's report (1993) lays out an argument in favor of an allied health generalist who handles all of a person's rehabilitation needs. Foto (1996) suggested that the commission does not understand that the various rehabilitation specialists like occupational therapy evolved out of need because of the difficulty of mastering the skills and knowledge required to meet every patient need. Foto continued by embracing the idea of multi-skilling non-skilled rehabilitation aides, defining which services require a professional occupational therapist, and incorporating transdisciplinary treatment teams.

Sheldon and Craig (1994) offered an insightful strategic discussion of the changing 
structures available to rehabilitation treatment teams. Multidisciplinary, interdisciplinary and transdisciplinary structures are outlined according to the characteristics of team focus, process, communication goals, problem solving, patient participation, and team member commitment. The transdisciplinary structure seems to best fit the managed care market due to its collaborative approach, patient centered focus, and functional outcome driven goals.

Rausch Rehabilitation Services surveyed Chicago area rehabilitation services manager and supervisors to see how they were coping with changes in the health care environment (Grace, 1995). A total of $95.4 \%$ reported experiencing changes involving reorganization, higher productivity expectations, adoption of new patient care programs, and the addition of new staff. The staff mix ratios seem to reflect an increase in the use of aides in the rehabilitation arena. A significant number of participants (43.9\%) also identified changes in delivery of patient care services, prioritizing patients for services or not providing treatment for some patients. In response to these changes, managers are allocating less time for staff development, hiring more part time employees, treating more patients in groups, cross training staff to improve productivity and meet patient needs, and expanding rehabilitation hours to include weekends. Many of these managers are multidisciplinary in nature and supervise occupational therapy, physical therapy and speech-language pathology. Many of these responses seem to be stopgap measures that are affecting the morale and retention of the therapists on staff (Grace, 1995). This survey offers clear indications of the need for the occupational therapy profession to strategically position itself and create initiatives to counter the negative aspects of managed care change. Although Rausch Rehabilitation Services gathered valuable data on managed care impact, its purpose was the investigation of staffing level changes in the market where they can provide contractual staffing services. The study did not address the effectiveness of these changes on services delivery, or whether these changes were driven by the hospital administration or the department managers. Practitioners need to know what effective initiatives are being proposed by occupational therapists in order to assume roles and responsibilities that will benefit their rehabilitation department's position. 
Spurred by member concerns, the American Occupational Therapy Association (AOTA), issued a pilot survey designed to assess the changing health care environment and develop recommendations for AOTA action (Pontzer, 1994). The survey results revealed the need for private practice occupational therapists to improve their value through the increased use of credentialing and by aligning with other disciplines to gain managed care contracts. The respondents also verified the limits imposed on patients due to reimbursement policies changes (Pontzer, 1994). AOTA urged OT practitioners to become familiar with managed care components, assist in the development of critical pathways of care, and educate case managers as to the benefit of occupational therapy. Although this survey was well intentioned, many aspects of its design could be enhanced. The target audience of the survey was not clearly defined in relationship to the questions which were posed. This may partially explain the low return rate of survey responses. Although every member of the AOTA was polled through the association's weekly magazine, only 143 responses were retumed. Many of the questions posed may have been aspects of managed care in which occupational therapists are not yet directly involved. The survey also did not focus on initiatives implemented by respondents and their subsequent effectiveness. The developers of the survey seemed to have recognized the shortcomings of this survey and are currently considering the release of an improved version to AOTA respondents.

\section{Conceptual Framework}

The managed care environment has given occupational therapists the occupational challenge of adapting the delivery of their services to fit the new reimbursement process (Joe \& Hettinger, 1995). Schkade and Schultz (1992) described occupational adaptation as a holistic approach to the process by which competence in occupational functioning develops. It gives equal importance to the person, the occupational environment and the person's experience of personal limitations and validations while interacting with the environment. This frame of reference examines the process by which someone adapts to environmental change and measures successful change outcomes by investigating (1) the degree of self initiation with a new task, (2) the ability to generalize the learned skill across 
situations and (3) the person's own judgment of their relative mastery of the skill.

Garrett and Schkade (1994) used occupational adaptation in a study to test the validity of a model of professional development with students. The model depicted three classes of adaptation behaviors: primitive, transitional and mature. The study demonstrated how changes in work roles that exceeded one's adaptive capacity were likely to produce increased primitive adaptation behavior. This circumstance will put one at risk for occupational dysfunction if not adequately prepared for (Garrett \& Schkade, 1994).

Given the dramatic transitions prompted by managed care, this frame of reference can be applied to the role adaptation process of occupational therapists as they encounter occupational challenges within the managed care environment. Improvement in the person's adaptation process is accomplished through occupational readiness and occupational activity (Schkade \& Schultz, 1992). Examples of occupational readiness skills for occupational therapy managers could include financial management training, time management, negotiation strategies, or networking development. Occupational activities put the benefit derived from this readiness into meaningful action (Schkade \& Schultz, 1992). Participation in the development of initiatives is a strong example of an occupational activity that occupational therapy managers can use to assist in a positive adaptation process within the managed care environment.

The Occupational Adaptation frame of reference which is used to heal individual patients can also be used to heal organizations. Using systems thinking, Sata (1989) contends that one form of organizational learning results from understanding and experiencing the changes occurring in the external environment and then adapting beliefs and behaviors in the process to be compatible with those changes. The way the planning process is structured and who is involved in it can make an important difference to success. Generative learning, which changes basic assumptions in order to apply transformational changes, is often overlooked in organizations in lieu of the more concrete form of corrective learning (Nevis, DiBella \& Gould, 1995). Just as individuals view problems from several different angles in order to generalize their learning and achieve mastery of 
new situations, so also do organizations. Managed care's focus is to correct overutilization of health care resources. In order for health care entities to survive, their focus should also be to investigate their organizational processes and culture, identify and alter basic assumptions which are negatively affecting their ability to change and achieve mastery in the managed care environment.

\section{Summary}

Managed care is creating a paradigm shift in the U.S. health care system. Over $65 \%$ of people with private insurance and $55 \%$ of the population as a whole are already covered by managed care plans (Joe \& Hettinger, 1995). Cost containment strategies are shifting every aspect of health care provider services delivery. This complex environment is causing occupational therapists to shift which clients are treated, where they treat their clients, who treats them directly, what they treat them for, and how much treatment they can give. The question is: What can occupational therapists do to positively affect the success and survival of the profession? ASHT president Donnell mourned the changes in client treatment and then encouraged success in the health paradigm by surfing that wave of change through the continual adaptation to changing consumer needs and the recognition of "the opportunities hidden in change" (Hettinger, 1995, p. 18). This research investigates the changes in occupational therapy services delivery, occupational therapist perceptions of how those changes are being adapted in the workplace, and educational opportunities that occupational therapists can undertake to best respond to those environmental and role changes. 


\section{Chapter 3}

\section{Research Desien}

\section{Purpose}

The purpose of this research was to assess the perceptions of occupational therapy directors regarding the impact of managed care on occupational therapy. The perceptions were investigated in ways that provided a clear picture of the following: (1) the changes in occupational therapy services delivery, (2) the attitudes that occupational therapy managers have about those changes in the workplace, and (3) the education that occupational therapists need to best respond to changes in their roles and environment. A clear understanding of the current national position of occupational therapy leaders is needed for the profession of occupational therapy to collectively position itself proactively within the changing health care environment.

\section{Research Questions}

1. To what degree do occupational therapy managers perceive organizational restructuring changes to be influenced by managed care demands?

2. How do occupational therapy staffing mix changes compare in California, . Illinois and New York?

3. Which clinical practice changes are identified by occupational therapy managers as altering the most dramatically in the last two years?

4. Which perceptions of managed care change are the most strongly held by occupational therapy managers?

5. What educational recommendations do occupational therapy managers make for health care professionals to help them successfully manage their careers within this changing environment?

\section{Research Design Development}

This study was conducted as a subset of a larger research effort focusing on managed care (Diasio Serrett, 1995). The entire study was comprised of both qualitative and quantitative research methods. Diasio Serrett and Duncan (1995) explored impact and 
perceptions of managed care in the form of focus groups and individual interviews with OT directors who were identified by colleagues as experts in managed care. Data from the qualitative portion of that study were used in the development of this study.

This study was conducted as non-experimental descriptive research utilizing a survey questionnaire that was sent to occupational therapy directors and private practice owners across the United States. Descriptive research is appropriate when the intent is to examine the way two variables are related to each other without necessarily having a causal relationship (DePoy \& Gitlin, 1994). The survey questionnaire method was chosen because it was the most feasible method for gathering information from a large pool of occupational therapy directors across the United States.

\section{Sample}

The sample consisted of 425 occupational therapy directors and private practice owners across the country. The subjects were drawn from professional director forum groups in areas such as Chicago, New York, Washington D.C., Kansas City, Atlanta, San Francisco Bay area, and Los Angeles. The private practice owners were drawn from a nation-wide listing provided by the American Occupational Therapy Association. All subjects were registered occupational therapists and identified themselves as being in a management position within their particular setting.

\section{Research Methodology}

\section{Instrumentation and Procedures}

This study used a five page questionnaire to gather data (See Appendix C). The content sections of the survey were designed to include demographics, involvement in managed care, changes in services delivery, perceptions of managed care changes in the workplace and educational areas recommended for occupational therapists.

Demographic data was gathered to aid in the analysis of the resulting data according to several independent variables (geographic location, type of organization, job position, type of practice and level of education). No attempts were made to control variables as only descriptive and correlational research was intended. 
The survey content was developed through review of the literature. To assure content validity, the survey content was refined after the analysis of the unpublished raw data collected through the qualitative subset of the larger study. The questions were conceptually framed in alignment with the works of Senge (1990) and Diasio Serrett and Gomes (1991).

The validity of the instrument was further verified by seeking the advice of two research experts knowledgeable in questionnaire design effectiveness. These experts assessed the clarity, conceptual framework, and layout of the questionnaire. Changes were incorporated based on their recommendations.

A pilot study for the survey was conducted with eight occupational therapy managers who had content expertise in a variety of clinical practice areas within the state of California. The pilot study attempted to assess clarity in question wording, overlapping content areas, and the length of time needed to complete the survey. If two or more participants noted a question as unclear or inappropriate, the question was reworded or eliminated. The questionnaire was revised at each step of the process until it assumed its final form.

\section{Data Collection and Analysis}

The revised questionnaire and a cover letter (Appendix B) which explained the purpose of the questionnaire was mailed to 425 sample subjects. A stamped, addressed return envelope was enclosed to increase the likelihood of response. A follow-up mail reminder was sent to professional director's forum group members in order to generate an increased response. A follow-up reminder was not sent to the private practice group when a preliminary data analysis of 19 respondents with private practice demographics revealed $42 \%$ percent of private practice respondents marking not applicable to 12 or more questions.

The services of a statistical consultant was used by the researcher to assist in the analysis of the data. Descriptive statistical tables were used to relate the demographic data. Both changes in managed care practices and manager perceptions of managed care changes 
in the workplace were rated by respondents on a Likert-type scale. Means and standard deviations were determined from those Likert-type scale ratings for each of the areas. Those means were then rank ordered. Frequencies were used to determine staffing mix levels, the prevalence of restructuring changes, and managed care's influence on these changes. The educational areas were rank ordered according to the percentage of respondents who perceived a need for that type of education.

\section{Resources}

The resources for this study were provided by two sources. Grant funds from the California State University (CSU) system were used to generate and mail the survey. San Jose State University Foundation provided a grant to further this investigation and present its findings at both state and national conference levels.

\section{Limitations}

The many factors limit the generalizability in this study. The following are all limiting factors: (1) All of the respondents were at the level of manager or higher and thus their perceptions may differ from those of staff therapists who work more directly with clients, (2) All respondents were active in directors' forum groups and/or AOTA and may demonstrate more proactive, initiative-based behavior than the average occupational therapy manager, (3) Respondents were primarily from urban areas, (4) Not all geographic areas in the United States were surveyed, and (5) respondents were a convenience sample of identified directors groups and private practice owners, and therefore survey results cannot be reliably generalized to other occupational therapy groups. 


\section{Chapter 4}

\section{Data}

\section{Introduction}

Of the 425 questionnaires mailed, 121 were returned (28.4\%). Two were not usable due to inappropriate setting and failure to complete the questionnaire. This yielded a final sample size of 119 , or $28 \%$ of the respondents.

The results and interpretation of the data follow in two sections: demographics and research findings. Each research question will be stated and then followed by analysis of the data and the results. Data are presented in both the narrative and table form. Where more than one answer was allowable, the total percentage is greater than one hundred percent.

\section{Demographics}

Five survey questions focused on demographic data. The demographic portion of the questionnaires queried the respondents as to their type of organization, major area of practice, job position, highest educational degree received, and geographic state of practice represented.

These demographic questions were divided into three tables. Table 1 outlines such organizational characteristics as organizational type and area of practice. Personalperformance characteristics such as job position and highest degree received are included in Table 2. The geographical state of practice for all respondents is outlined in Table 3.

\section{Organizational demographic characteristics. Question 8 of the} questionnaire asked respondents to check the type of organization which best described their work setting (Table 1). There were 119 responses to this question. Fifty-four percent of respondents described non-profit organizations, $22 \%$ came from private practice settings, $12 \%$ described other for-profit organizations, $6 \%$ came from county-affiliated facilities, $4 \%$ came from state-affiliated facilities, and $2 \%$ described contracting organizations.

Of the 117 total respondents, over $46 \%$ checked more than one response to describe 
Table 1

Organizational Demographic Characteristics of Respondents

\begin{tabular}{lc}
\hline Variable & Responses \\
& $\begin{array}{c}\text { Percentage } \\
\text { of All Respondents }\end{array}$ \\
\hline
\end{tabular}

Type of organization $(n=119)$

5

4.2

County

8

6.7

Other non-profit organization

64

53.8

Contracting organization

2

1.7

Private Practice

26

21.8

Other for-profit organization

14

11.8

Major area of practice $(n=171)$

Hand therapy

37

21.6

Geriatrics

9

5.3

Pediatrics

22

12.9

Physical disabilities

73

42.7

Mental health/behavioral health care

16

9.3

Prevention/wellness

6

3.5

Other

8

4.7

Note. $n=$ all of the surveyed responses to the individual demographic question. 
Table 2

\section{Personal-Performance Demographic Characteristics of Respondents}

\begin{tabular}{ll}
\hline Variable & Responses \\
& $\begin{array}{c}\text { Percentage } \\
\text { of All Respondents }\end{array}$ \\
\hline
\end{tabular}

Job position $(n=118)$

Supervisor/lead therapist

46

39.0

Middle management

41

Upper management

8

6.8

Practicing owner/partner

23

19.5

Highest degree received $(n=118)$

Baccalaureate degree

69

Master's degree

48

40.7

Doctorate degree

1

.8

Note. $n=$ all of the surveyed respondents who replied to the individual demographic question. 


\section{Table 3}

\section{Geographical State Represented by Respondents}

\begin{tabular}{|c|c|c|}
\hline State & Responses & $\begin{array}{l}\text { Percentage } \\
\text { of All Respondents }\end{array}$ \\
\hline California & 42 & 35.9 \\
\hline New York & 23 & 19.7 \\
\hline Illinois & 17 & 14.5 \\
\hline Georgia & 5 & 4.3 \\
\hline Missouri & 5 & 4.3 \\
\hline Texas & 5 & 4.3 \\
\hline Kansas & 2 & 1.7 \\
\hline Maryland & 2 & 1.7 \\
\hline Minnesota & 2 & 1.7 \\
\hline New Jersey & 2 & 1.7 \\
\hline North Carolina & 2 & 1.7 \\
\hline Virginia & 2 & 1.7 \\
\hline Washington & 2 & 1.7 \\
\hline Colorado & 1 & .8 \\
\hline Florida & 1 & .8 \\
\hline Massachusetts & 1 & .8 \\
\hline New Mexico & 1 & .8 \\
\hline Rhode Island & 1 & .8 \\
\hline South Carolina & 1 & .8 \\
\hline
\end{tabular}


their major area of practice (see Table 1). Almost $43 \%$ of the respondents practiced in physical disabilities settings, almost $22 \%$ of the respondents specialized in hand therapy, close to $13 \%$ of the respondents specialized in pediatrics, $9 \%$ practiced in mental health/behavioral health care settings, $5 \%$ specialized in geriatrics, over $3 \%$ practiced in prevention and wellness and the remaining $5 \%$ practiced in other areas such as industrial medicine.

Personal-performance demographic characteristics. Current job positions were identified by one hundred eighteen respondents (see Table 2). Of 118 participants responding to current job position, $39 \%$ were supervisor/lead therapists, $35 \%$ of the respondents best identified themselves as middle management, $7 \%$ best identified themselves as upper management, and the remaining one fifth of respondents were titled practicing owner/partners.

One hundred eighteen respondents identified the highest degree they received (see Table 2). Almost fifty-nine percent of respondents held baccalaureate degrees, close to $41 \%$ held master's degrees where as only one respondent held a doctoral degree.

Geographical state. Geographic representation is shown in Table 3. The largest percentage of responses came from California (35.9\%), followed by New York (19.3\%), and Illinois (14.5\%). Georgia, Missouri, and Texas each claimed $4 \%$ of respondents. Only 2\% each hailed from Kansas, Maryland, Minnesota, New Jersey, North Carolina, Virginia, and Washington. Colorado, Florida, Massachusetts, New Mexico, Rhode Island, and South Carolina were each represented by a single respondent.

\section{Research Findings}

The first objective of the study was to assess the impact of managed care on changes in occupational therapy services delivery. Research questions 1,2 and 3 were posed in order to further analyze the impact of managed care on both the organizational restructuring, staffing mix and clinical practices of occupational therapy agencies. 
Question 1. To what degree do occupational therapy managers perceive organizational restructuring changes to be influenced by managed care demands?

Respondents were asked to what extent have managed care contracts been an influence in organizational changes (see Table 4). Almost 53\% reported managed care contracts had a major influence in their organizational changes, almost $35 \%$ cited some influence, $10 \%$ reported no managed care influence on organizational change and $2.7 \%$ cited no exposure to managed care.

Question 2. How do occupational therapy staffing mix changes compare in California, Illinois and New York?

This question allowed us to compare three distinct urban areas in different parts of the country for staffing changes which occurred in the last 2 years (see Table 5). The questionnaire offered the selection of an increase or decrease in staffing for registered occupational therapists (OTRs), certified occupational therapy assistants (COTAs) and aides. Of the 106 respondents indicating a change in staffing, 41 were from California, 21 were from New York, and 16 were from Illinois.

In California, $61 \%$ of the respondents indicated both an increase in aides and a decrease of registered occupational therapists. This was countered by only $22 \%$ of California respondents indicating an increase in registered occupational therapists and 7.3\% indicating a decrease in aides. More certified occupational therapy assistants were added than eliminated from the California staff mix. Almost $37 \%$ of respondents identified an increase in certified occupational therapy assistant staffing as compared to only $19.5 \%$ who identified a decrease in certified occupational therapy assistants on staff.

An overwhelming $75 \%$ of Ilinois respondents identified a decrease in registered occupational therapists as compared to a mere $13 \%$ indicating an increase in registered occupational therapist staffing. Both certified occupational therapy assistants and aides demonstrated increased staffing levels with $31 \%$ of the Illinois respondents. In comparison, only $25 \%$ of respondents decreased certified occupational therapy assistant aff levels and a mere $13 \%$ of respondents decreased aide staff levels. 
Table 4

Influence of Managed Care Contracts on Organizational Changes $(n=110)$

Extent of Influence

Major
Some
None
No exposure to managed care

Responses

58

38

11

3

8

1

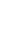

Percentage of

All Respondents 52.7

34.6
10.0

2.7

Note. $n=$ all of the surveyed respondents who replied to the individual demographic question. 
Table 5

Qccupational Therapy Stafing Mix Changes in Last Two Years

\begin{tabular}{|c|c|c|c|c|c|c|}
\hline Staff Type & $\begin{array}{l}\text { California } \\
\text { Responses } \\
(n=41)\end{array}$ & $\%$ & $\begin{array}{l}\text { Illinois } \\
\text { Responses } \\
(n=16)\end{array}$ & $\%$ & $\begin{array}{l}\text { New York } \\
\text { Responses } \\
(n=21)\end{array}$ & $\%$ \\
\hline \multicolumn{7}{|l|}{ Aides } \\
\hline Increase & 25 & 61.0 & 5 & 31.2 & 4 & 19.0 \\
\hline Decrease & 3 & 7.3 & 2 & 12.5 & 3 & 14.3 \\
\hline \multicolumn{7}{|c|}{ Certified Occupational Therapy Assistants (COTAs) } \\
\hline Increase & 15 & 36.6 & 5 & 31.2 & 8 & 38.1 \\
\hline Decrease & 8 & 19.5 & 4 & 25.0 & 0 & 0.0 \\
\hline \multicolumn{7}{|c|}{ Registered Occupational Therapists (OTRs) } \\
\hline Increase & 9 & 22.0 & 2 & 12.5 & 11 & 52.4 \\
\hline Decrease & 25 & 61.0 & 12 & 75.0 & 6 & 28.6 \\
\hline
\end{tabular}

Note. $\mathrm{n}=$ all of the surveyed respondents who replied to the individual demographic question. $\%=$ percentage of those " $n$ " respondents who replied with the indicated staffing mix change. 
In stark contrast, New York respondents reported more increases than decreases across all staff levels. Over $52 \%$ of the respondents identified an increase in registered occupational therapists versus $29 \%$ who reported a decrease in the registered occupational therapists in their staff mix. An increase in certified occupational therapy assistant staffing levels was also indicated over $38 \%$ of respondents versus no reported decreases in certified occupational therapy assistant staffing. Nineteen percent of New York respondents reported an increase in the use of aides and were closely followed by $14 \%$ who reported an decrease in the staffing of aides.

To more fully understand these staffing comparisons, two additional areas were analyzed: 1) organization status in relation to managed care and 2) length of time each practice setting has had managed care contracts. Frequencies were used to examine the organizations' relationship to managed care (see Table 6). Means and standard deviations (see Table 7) were used by state to compare the reported length of time each practice setting has had managed care contracts.

Respondents were asked to describe their organization's relationship to managed care in one of three ways: implementation of service changes, involvement in preparation for contracts or not yet directly affected in clinical practice. An overwhelming majority of respondents in all three states cited service change implementation due to managed care contracts. Sixty-eight percent of respondents in California reported being in the implementation phase as compared to approximately $57 \%$ of respondents in both Illinois and New York. New York respondents (38\%) were more actively involved in preparation for managed care than those in either Illinois (25\%) or California (23\%). Fewer in New York $(5 \%)$ remained unaffected in clinical practice by managed care in comparison to California (10\%) and Illinois (19\%).

New York respondents ( 1.7 years) also reported a shorter history of managed care contracts than did California ( 3.4 years) or Illinois ( 4.5 years). Interestingly, the standard deviations showed a wider variance of managed care contract history in Ilinois (3.30) and California (2.70) than in New York (.75). 
Table 6

Organization Status in Relation to Managed Care

\begin{tabular}{|c|c|c|c|}
\hline Status & $\begin{array}{l}\text { California \% } \\
(n=41)\end{array}$ & $\begin{array}{l}\text { Mlinois \% } \\
(n=16)\end{array}$ & $\begin{array}{l}\text { New York \% } \\
(n=21)\end{array}$ \\
\hline Not yet directly affected in practice & 10.00 & 18.75 & 5.00 \\
\hline Involved in preparation for contracts & 22.50 & 25.00 & 38.00 \\
\hline Implementing service changes & 67.50 & 56.25 & 57.00 \\
\hline
\end{tabular}

Note. $n=$ all of the surveyed respondents in the state who replied to the individual demographic question. $\%=$ percentage of those " $n$ " respondents who replied with the indicated status. 
Table 7

Length of Time Each Practice Setting Has Had Managed Care Contracts

\begin{tabular}{llr} 
State & Mean & $\underline{\text { SD }}$ \\
\hline New York & 1.7 years & .75 \\
California & 3.4 years & 2.29 \\
Illinois & 4.5 years & 3.30
\end{tabular}

Note. $\underline{\mathrm{SD}}=$ standard deviation. 
Question 3. Which clinical practice changes are identified by occupational therapy managers as altering the most dramatically in the last two years?

Respondents were asked to indicate the amount of changes they have seen across 14 clinical practices in order for their organizations to be competitive (see Table 8). A Likert-type scale of $1-5$ was presented with " 1 " equal to strong increase, " 2 " equal to slight increase, "3" equal to neutral, "4" equal to slight decrease, "5" equal to strong decrease, and "N/A" equal to not applicable to their setting. The clinical practice areas identified as having increased dramatically were defined for the purposes of this study to be those with mean scores less than 2.00 .

According to the results of the survey, four clinical practice areas have increased dramatically. Cost management planning and procedures have increased the most and is noted by the lowest mean score (1.53). Patient/caregiver education efforts received the next rated increase with a mean response of 1.69. Case management was third with a mean of 1.74. Continuous quality improvement efforts also showed significant increase with a mean of 1.85. Other clinical areas from the survey also have increased; however, practice changes in those areas were not perceived as increasing as significantly (Table 8). Those clinical practice areas in order from lowest to highest mean score include competency validation/credentialing efforts (2.00), new program/product line development (2.02), time spent doing clerical/administrative tasks (2.04), transdisciplinary treatment evaluation/planning (2.06), occupational therapy (OT) services integrated across care continuum (2.24), patients treated in groups (2.34), middle managers performing direct client care (2.43), selection of personally meaningful client activities (2.48), physical agent modality use (2.55), and time spent by registered occupational therapists (OTRs) in direct client care (2.92).

The second objective of the study was to explore the attitudes that occupational therapy managers have of those changes in the workplace. This objective was addressed in research question 4 . 
Table 8

Clinical Practices Which Have Altered the Most in the Last Two Years

\begin{tabular}{llll}
\hline Clinical Practice & Total & Mean & $\underline{\text { SD }}$ \\
& respondents & & \\
\hline Cost management planning and procedures & 115 & 1.53 & .60 \\
Patient/caregiver education efforts & 113 & 1.69 & .66 \\
Case management & 112 & 1.74 & .72 \\
Continuous quality improvement efforts & 117 & 1.85 & .73 \\
Competency validation/credentialing efforts & 113 & 2.00 & .64 \\
New program/product line development & 103 & 2.02 & .66 \\
Time spent doing clerical/administrative tasks & 114 & 2.04 & .77 \\
Transdisciplinary treatment evaluation \& planning & 107 & 2.06 & .69 \\
OT services integrated across care continuum & 110 & 2.24 & .75 \\
Patients treated in groups & 97 & 2.34 & .85 \\
Middle managers performing direct client care & 95 & 2.43 & .76 \\
Selection of personally meaning client activities & 110 & 2.48 & .81 \\
Physical agent modality use & 85 & 2.55 & .86 \\
Time spent by OTRs in direct client care & 116 & 2.92 & .82 \\
\hline
\end{tabular}

Note: A lower number indicates a stronger increase. 
Question 4. Which perceptions of managed care change are the most strongly held by occupational therapy managers?

Research question $\mathbf{4}$ considers the responses to 36 statements concerning workplace perceptions from the questionnaire. Each respondent was asked the degree to which they agreed or disagreed with each statement about their workplace (see Table 9). A scale of 1-5 was presented with " 1 " equal to strongly agree, " 2 " equal to agree, "3" equal to neutral, "4" equal to disagree, " 5 " equal to strongly disagree, and "N/A" equal to not applicable to their setting. The most strongly held perceptions were defined for the purposes of this study to display two criteria: (1) the response average (mean value) equal to 2.00 or less to denote strong agreement or equal to 4.00 or more to denote strong disagreement and (2) standard deviations less than or equal to 1.00 to tighten the response variance from the mean.

Six perceptions of their organizations' change were strongly held by occupational therapy managers. Although both agreed with and disagreed with responses were examined, all of the strongly held perceptions denoted agreement. These perceptions, which are listed in order of agreement, include:

1. We take the time to make sure clients clearly understand their rehabilitation benefits and how these relate to their recovery.

2. A strong focus on our clients' satisfaction pervades all levels of staff.

3. We are frustrated by the limitations imposed on our professional expertise by managed care contracts.

4. We frequently request client feedback on care quality and incorporate their priorities into our care process.

5. Timely client care has been hampered by managed care policies and procedures.

6. Insurance case managers' lack of understanding of our health care role has resulted in loss of referrals for needed client care.

The third objective of the study was to provide a picture of the education that occupational therapists need to best respond to role and environmental changes. Research question five addresses this objective. 


\section{Table 9}

\section{Workplace Perceptions Strongly Held By Occupational Therapy Managers}

1. We take the time to make sure clients clearly understand their rehabilitation benefits and how these relate to their recovery. $\quad 1.71 \quad .76$

2. A strong focus on our clients' satisfaction pervades all levels of staff. $\quad \begin{array}{lll}1.80 & .87\end{array}$

3. We are frustrated by the limitations imposed on our professional expertise by managed care contracts.

4. We frequently request client feedback on care quality and incorporate their priorities into our care process.

5. Timely client care has been hampered by managed care policies and procedures.

6. Insurance case managers' lack of understanding of our health care role has resulted in loss of referrals for needed client care.

7. Cost containment has in fact outweighed other aspects of restructuring despite statements made about maintaining or enhancing quality

8. Clinical staff spend significantly more non reimbursed time talking with insurance companies or other entities to get authorization for client treatment

9. A large gap exists between the care the patient expects and the care we can deliver under managed care coverage 
Table 9

(continued page 2 of 4 )

Workplace Perceptions Strongly Held By Occupational Therapy Managers

10. We have been actively promoting activities such as health fairs, wellness and prevention workshops, support groups, and other community outreach efforts.

$2.19 \quad .89$

11. Staff dedication to our organization's mission and vision helps us take pride in our service and staffing priorities.

12. There are many areas needing change in this system which are not being addressed by work on clinical pathways.

13. Our organization has been giving clinical staff a better picture of health care trends and how those trends relate to services we need to provide.

14. Clinical staff have been coached in ways to develop new programs to better meet needs of targeted populations.

15. Middle-level managers are informed and participate in decision making about proposed clinical service changes.

16. Clinicians are often put in ethical binds because of limitations in managed care contracts.

17. Interdisciplinary clinical pathways have helped us better define our work processes.

18. Work requiring the team efforts of different clinical disciplines now gets done more smoothly. 
Table 9

(continued page 3 of 4 )

\section{Workplace Perceptions Strongly Held By Occupational Therapy Managers}

19. We have created task forces to identify and eliminate underlying causes of work process problems.

20. Managed care contracts have made our clinicians more accountable for efficient and effective client care.

21. Reimbursement/administrative policies have caused significant problems in implementing a continuum of care.

22. Many change efforts have been at cross purposes and have created confusion and wasted effort.

23. Time and financial resources have been committed to support lifelong learning for clinical staff.

24. Our current functional outcome measures are so general that they don't adequately measure OT's capacity for intervention.

25. Cross disciplinary change efforts have been inclusive of all staff levels and professions.

26. We have worked on defining our unique strengths, and built on those, and let go of "being all things to all people"

27. A strong level of trust and open dialogue is being developed between management and clinical staff.

28. This organization has been conscientious about paying attention to the human aspects of change for employees. 
Table 9

(continued page 4 of 4 )

Workplace Perceptions Strongly Held By Occupational Therapy Managers

Mean $\underline{S D}$

29. We are actively involved in working with employers directly in determining health needs of their employees.

30. Our organization rewards staff initiatives that lead to innovations in clinical services and work processes.

31. Clinical staff have not yet changed their perspectives to include understanding the what and why of organizational changes that are occurring.

32. We have seen definite improvement in the quality of services to patients as a result of our change efforts.

33. Advocacy for patients has resulted in warnings or reprimands from health care plan representatives.

34. We have computerized information to enhance our productivity with documentation and outcomes research.

35. Our partnerships with our managed care /third party payers have been mutually satisfactory.

36. Clinical staff rarely participates in gaining continuous quality improvement and work process redesign skills. 
Question 5. What educational recommendations do occupational therapy managers make for health care professionals to help them successfully manage their careers within this changing environment?

The questionnaire gathered perceptions of 36 statements about the workplace. After each statement which queried workplace perceptions, respondents were asked to check the line if they would recommend further education for occupational therapists in that area (see Table 10). Five educational areas were checked by at least $20 \%$ of the respondents.

Thirty-one percent of those responding would seek training in coaching clinical staff to develop new programs to meet targeted populations. This was closely followed by almost $30 \%$ of respondents who expressed an interest in how to develop mutually satisfactory relationships with managed care/third party payers. Community health promotion and prevention activity education was recommended by almost $23 \%$ of responding managers. This was closely trailed by almost $22 \%$ who indicated occupational therapists should seek more education in functional outcomes that measure occupational therapy's capacity for intervention. Finally, 20\% of respondents wanted education for their staff to understand the what and why of occurring organizational change. 
Table 10

\section{Need for Occupational Therapist Education}

Educational Topic $(n=119)$

Respondents $\quad \%$ of total

recommending respondents

further education

1. Coaching staff in ways to develop new programs to meet targeted populations.

2. Mutually satisfactory relationships with managed care/third party payers.

3. Promoting activities such as health fairs, wellness and prevention workshops, support groups, and other community outreach efforts.

4. Functional outcome measures that measure OT intervention. 26

5. Staff education to understand the what and why of occurring organizational changes.

6. Client education of rehabilitation benefits related to their personal recovery.

7. Interdisciplinary clinical pathways.

8. Computerized productivity tools.

9. Staff education in continuous quality improvement and work process redesign.

10. Working directly with employers on employee health needs. 
Table 10 (continued page 2 of 3 )

Need for Occupational Therapist Education

Educational Topic ( $n=119)$

Respondents \% of total

recommending respondents

further education

12. Insurance case manager education of OT role and capabilities. 12

10.1

13. Defining \& building on OT role and strengths.

14. Ethical dilemmas with managed care contract limitations.

15. Team building across disciplines.

16. Staff education relating health care trends to service provision. 11

17. Timely client care with hampering managed care policies. $\quad 10$

18. Negotiating with payers for treatment authorization.

19. Administrative policies that hinder care continuity.

20. Cost containment and quality improvement.

21. Clinician accountability for efficient/effective care.

22. Professional expertise frustration and managed care limitations. 7

23. Staff education on human aspects of organizational change. 6

24. Change efforts inclusive of all staff levels and professions. 6

25. Incorporating client satisfaction feedback into care process. 6

26. Care gap between client expectations and services coverage. 6

27. Integration/consistency of purpose in change efforts.

28. Staff use of organization's mission to prioritize service.

29. Work process changes not covered in clinical pathways. 
Table 10 (continued page 3 of 3 )

Need for Occupational Therapist Education

Educational Topic

Respondents $\quad \%$ of total

recommending respondents

further education

30. Trust/dialogue between staff and management. 5

31. Task forces to target underlying work process difficulties.

4

32. Quality improvement of services.

3

2.5

33. Rewarding staff innovations and initiatives

3

2.5

34. Staff development/supported learning

3

2.5

35. Middle manager involvement in change

2

1.7

36. Patient advocacy

1

.8 


\section{Chapter 5}

\section{Discussion}

In this chapter the results of the study will be discussed as they relate to the literature review and the Occupational Adaptation frame of reference. Recommendations for further research will follow a discussion of the implications of those results.

\section{Organizational Change \& Managed Care Influence}

Over $87 \%$ of the respondents indicated that managed care contracts were influencing change in their organization. The results of this study confirm the increase in health care entity reorganizational changes noted by Grace (1995). Grace's study cited 95\% of surveyed Chicago area health care professionals experiencing facility change in such areas as staff restructuring, higher productivity expectations, new patient care programs, and services delivery. Another confirming study by Lumsdon and Haglund (1993) found that $57 \%$ of surveyed hospital executives had restructuring plans stemming from the development of formal initiatives to monitor and manage clinical processes.

More importantly, almost 53\% of survey participants perceived managed care contracts to have had a major influence in those changes. This also coincides with Lumsdom and Haglund (1993) who found that $52 \%$ of respondents cited managed care penetration as the key circumstances leading to clinical process changes. Given the historical effect of how reimbursement related changes can alter the direction of the occupational therapy profession (Howard, 1991), it is clear that occupational therapists need to strategically address these challenges in order to adapt to workplace change with greater success.

\section{Comparisons Across Geographical Areas}

Use of aides and certified occupational therapy assistants (COTAs) in staffing mixes has reportedly increased for respondents across all three regions. Both Ilinois and California reveal a sharp decrease in the staffing of registered occupational therapists (OTRs), a mild increase in certified occupational therapy assistants and a stronger increase in the use of aides. In contrast, New York respondents reported a strong increase in the 
use of registered occupational therapists and certified occupational therapy assistants and a slighter increase for aides.

Coile's (1994) identification of the stages that hospital markets go through as they integrate under managed care may hold a partial explanation for such a contrast in the use of registered occupational therapists. Markets experiencing early transition such as New York are developing staff and creating care alliances in preparation for managed care contracts. Markets experiencing later transition such as Illinois or California are experiencing reduced staffing levels to prune costs and consolidate clinical services as managed care penetrates the market.

This study's comparative analysis of each state's organizational status in relation to managed care adds credence to Coile's premise. New York respondents were more apt to be involved in the preparation phase for managed care contracts than either Califormia or Illinois. This analysis was confirmed by examining the length of time respondents reported having contracts with managed care entities. Both California and Illinois respondents cited longer involvement with managed care contracts; however, a wider variance of opinion existed as to the length of involvement time as compared to New York. Further research is needed to determine the significance of the wide opinion variance from both California and Illinois respondents. Is this variance due to resistance to embrace managed care contracting or do other variables exist in those organizations that have impacted the development of managed care contracts?

The 1993 American Occupational Therapy Association (AOTA ) Representative Assembly resolution noted that lack of knowledge of the certified occupational therapy assistant (COTA) role can create misuse by under- or over-utilization (Hettinger, 1995). Results from this research question validate such concerns. While some states like New York show a promising future for the certified occupational therapy assistant role as shown by a staffing increase of $38 \%$ with no corresponding reports of role decreases; other states such as Illinois show little difference between the increase and decrease in COTA staffing. 


\section{Clinical Practice Changes}

Four clinical practices have altered the most in the last two years: cost management planning and procedures, patient/caregiver education efforts, case management and continuous quality improvement efforts. The stress of all of these work role changes could diminish a therapist's personal health and job performance if the transitions to these changes are not adequately prepared for.

Cost management planning and procedures come as a response to the managed care question of how to deliver medical services at a lower cost. Foto (1988a) discussed the adaptational challenge cost containment brings to occupational therapists as they are asked to redefine traditional quality of care standards by balancing potential client recovery with care costs. As a result, health care providers including occupational therapists need to understand the world of business and financial management strategies in order to leam how to provide quality services within tighter parameters. In a survey which examined the needs of occupational therapy managers for advanced management training, Diasio Serrett and Gomes (1991) confirmed the current importance of business and entrepreneurial skill development. Particular emphasis was placed on transition management, strategic planning, and the incorporation of outcomes research into practice.

Patient/caregiver education efforts were identified by survey respondents as strongly increasing. The decrease in hands-on therapist care and the increase in patient care limits noted by Pontzer (1994) has motivated several rehabilitation facilities to increase patient and caregiver education efforts in an attempt to ask patients to be more self reliant in their recovery and prevention efforts. A consumer survey sponsored by the Bay Area Business Group on Health found higher satisfaction with HMOs who provided patient education for prevention and health improvement programs (Olmos, 1994). Landry and Knox (1996) identified the need for occupational therapists to consider a reduction in the procedures and modalities for any given patient treatment, a reengineering of the processes of care and requiring patients to do more for themselves. It seems clear that the increase in patient education has given occupational therapists both opportunities and responsibilities. 
Patient education approached from a preventative perspective could improve overall consumer self-advocacy and self-reliance for personal wellness. Increased responsibility, however, is needed to insure that patient education isn't a mere cost cutting measure to reduce direct treatment time for clients who are clearly at risk to lose function and need assistance to process those healthier practices and incorporate them into their daily living environment. How much education will clients retain when they are still reacting to the stages of grief associated with a newly acquired disability? Timing and a compliant mental state are critical components needed to transform newly learned information into healthy habits. Follow through on these habits often hinge on the therapist's timing in addressing these topics and the provision of a safe, supportive environment from which to ask questions and experiment with new behavior.

Case management, the survey's third strongly increased clinical practice, is the integration of all elements of a client's treatment to achieve maximum efficiency in both cost and treatment effectiveness. This research validates Fisher's (1996) suggestions that case management showcases occupational therapists' skills and offers the profession a natural leadership role within the managed care environment. Case management exists as a "gatekeeper" for treatment in many different practice settings and serves such fundamental goals as "cost containment, client empowerment and quality care" (Hettinger, 1996).

Continuous quality improvement efforts were reported as the fourth strongly increased aspect of change in clinical practice. The Joint Commission on Accreditation of Health care Organizations (JCAHO) shifted its focus from quality assurance to continual quality improvement as part of their accreditation requirements (Marszalek-Gaucher \& Coffey, 1990). Pontzer (1994) reported accreditations like JCAHO are used by several managed care entities when deciding whether to contract with service providers. Involvement in a quality improvement program can more often be driven by the need to look good in the eyes of the payers rather than the need to alter organizational trouble spots that affect quality of care. A clear distinction can be drawn between those entities tinkering with redesigning care and those which are committed to quality and are prepared to devote 
the time and resources needed to achieve dramatic, lasting change. Lumsdon and Haglund (1993) noted $92 \%$ of their survey respondents cited quality improvement as a top management strategic objective, yet over $40 \%$ lacked the information technology, knowledge/training and physician support to successfully develop corresponding improvements.

\section{Managed Care Change Perceptions}

Six strongly held workplace perceptions were noted by the occupational therapy managers who responded. Three of these perceptions emphasized collaboration with the client. These include: time is taken so clients clearly understand their rehabilitation benefits and how these relate to recovery, a strong focus on our clients' satisfaction pervades all levels of staff, and lastly, client feedback on care quality is frequently requested and incorporated into our care process.

Collaboration with the client in guiding services delivery and treatment decisions has long been a professional value of occupational therapy. This value has increasingly been embodied in managed care influenced practices and trends (Christiansen, 1996).

Client understanding of rehabilitation benefits and their subsequent impact on personal recovery attempts to increase patient self advocacy for needed services. Clinicians throughout the health care system have become "stewards of resources" who are sensitized to their responsibility to develop optimal recovery treatment plans consistent with patients' health care coverage (Joe, 1995). Managed care is mobilizing therapists through the reduction of coverage to move patients quickly through the system. Instilling the patient with an education of the reimbursed rehabilitation system and available community resources is one attempt used to achieve the abbreviated time frames with minimal compromises in patient well-being. Patients' rights to be informed of care benefits and freedom of speech between patients and health care professionals are highly politicized topics of debate. Some state governments are seeking to regulate managed care company activities in response to related grassroots lobbying efforts (California Secretary of State, 1996). 
Lumsdon and Haglund (1993) cited improved client satisfaction is a motivator for over $80 \%$ of respondents who are redesigning care. They also identified an increased sense of team effort in the staff that corresponded to an increased emphasis on understanding the bigger, interdepartmental picture of patient satisfaction.

Asking clients what they think about their service is an important component of outcomes measurements. The process of conducting and analyzing feedback on customer satisfaction has provided facilities with three major benefits: (1) benchmarking comparisons, (2) facilitation of continuous quality improvement initiatives by pinpointing concerns, and (3) improved staff morale by pointing to high levels of customer satisfaction of programs and/or individuals (Vogel, 1996). The Rehabilitation Accreditation Commission include a major emphasis on consumer input and satisfaction surveys in their quality improvement accreditation standards (Pontzer, 1994). Managed care organizations use report cards in such areas as patient satisfaction when negotiating provider contracts (Ellek, 1995).

The other three perceptions emphasized limitations associated with utilization management. These include: frustration over limitations imposed on professional expertise, untimely client care, and lastly, a lack of understanding of occupational therapy's health care role creating a loss of referrals. All of these perceptions point to a need for advocacy for both the patient and the profession. The administrative process described by Landry and Knox (1996) to inject cost considerations into the medical decision-making process facilitates understanding how policies and procedures can contribute to inadequate, untimely care. Concern over professional expertise limitations has also motivated political activism (Pontzer, 1996). Critics are lobbying in support of managed care standards which require qualified health care professionals to make care decisions and to involve professionals trained in the care under consideration.

Even though half of these workplace perceptions involve collaboration with the client, an alarming lack of coordination and common purpose remains amongst the stakeholders involved in care decisions. A staff-wide client satisfaction focus is one 
positive attempt to maintain quality of care; however, it is just one aspect of quality. Such attempts seem fruitless when the communication of client needs and implementation of treatment solutions fail to be timely and are often limited by poor understanding of occupational therapy's role and expertise. How such limitations impact the long term consequences of patient care was researched by Horn at the Institute for Clinical Outcomes Research in Managed Care at the University of Utah (Joe, 1996).

Horn's recent study of the clinical effects of HMO cost containment practices found that restricted formularies and other "yes/no" solutions tend to produce an increase in patient reliance on prescription drugs and may have unintended cost consequences, such as cost shifting elsewhere. This can pose as an ethical dilemma to those in a profession like occupational therapy, which is based on the reciprocal relationship between doing and health, versus the pharmaceutical masking of symptomology. Van Leit (1996) also found in mental health that cost containment reflected more of an unmet need or a shifting of the costs of care to the family and community. Treatment effectiveness must have mutually agreed upon parameters and be gauged in relation to long-term consequences, not just cost containment and short term service satisfaction.

\section{Managers' Recommendations For Further Education}

The strongest educational recommendations for occupational therapy managers lay in the following areas: (1) new program development for targeted populations, (2) positive relationships with reimbursers, (3) community health/prevention, (4) functional outcomes, and (5) staff education to manage workplace change. Both new program development and community health/prevention represent strong initiatives to increase occupational therapy's competitive edge through the enhancement of services delivery. Offering health promotion programs and targeting more costly diseases are methods that providers are using to reduce their utilization rates and subsequently their costs (Landry \& Knox, 1996). A study performed by Lewin-VHI, a health care policy consulting firm, found in opportunities in managed care exist for those who have an entrepreneurial mindset and can make their case to payers and land significant contracts (Hettinger, 1996). 
Staff education to understand the what and why of occurring organizational changes and the development of mutually satisfactory relationships with managed care/third party payers both demonstrate the need for education in change paradigms with cultural and interaction components. Sata (1989) has asserted that one of the highest leverage points for improving system performance is the minimization of system delays by defining more of a shared understanding from which a working trust can develop. This interaction would focus on the preparedness and functioning capabilities of each discipline as to what could be brought to the service mix. Inservices both to staff and to third party payers are two methods currently used by survey respondents to develop such trust.

Functional outcomes that measure occupational therapy's capacity for change have also been recommended for increased educational focus. Measuring the effectiveness of care will help occupational therapists determine clinical guidelines that outline clinical reasoning and assist the providers in proving the efficacy of their services delivery. Fear of losing control of treatment has dissuaded several health care professions from measuring care effectiveness (Ellek, 1995). Such fears have been created by concerns that guidelines developed solely through procedural reasoning will diminish the value of professional expertise shown through other forms of clinical reasoning. All forms of clinical reasoning are needed to account for client individuality and form the basis for individualized treatment success (Fleming, 1993). Managed care gatekeepers' lack of understanding of how such interactive reasoning can change the procedure guidelines has led to reimbursement difficulties when treating for individual differences.

Lack of initiative in developing sound functional outcomes has made occupational therapy as well as other disciplines appear subjective and lacking in professional expertise (Van Leit, 1996). By becoming involved in outcome research, providers may be able to focus more directly on cost-effective best practices which account for client individuality as opposed to mere cost-control of services.

\section{Implications}

Marszalek-Gaucher and Coffey (1990) approximate $85 \%$ of quality problems in 
health care are related to system and process design and need the support of all parties involved for positive change. Staff understanding of the what and why of the change process is needed to avoid employee resistance that will impact the program's success. Lumsdon and Haglund (1993) noted two significant process design components to promote long term use of care paths: (1) case management to determine if the care paths are working as planned and (2) automation tools to streamline work processes. Pathway charting and related documentation can mean even more paperwork for care giving staff members and subsequently lead the staff to rebel unless solutions are found to streamline those processes.

The need for staff and system changes have increased the overall stress level of rehabilitation managers as they are asked to question how much increased productivity can be attained from their staff without an increase in service costs. Thiers (1994) noted this trend as being used to streamline operating budgets. Some rehabilitation facilities are noting productivity expectations of one OT and one aide seeing three patients in an hour as compared previous standards of one OT treating one patient in one hour (Joe \& Hettinger, 1995). Many managers feel ethical conflict over the pressures of increasing low cost noncertified staff when a higher level of therapist skill is needed to achieve good patient outcomes within a more compressed time frame (Joe, 1996). Ethical conflicts continue with the therapists as they are faced with an increased patient load and having to transition to giving less intensive and hands-on care because more documentation, treatment authorization and aide supervision is required in the same amount of treatment time.

Quality of care concerns under such staffing mix changes has led to the development of competency programs for aides and the AOTA position paper on occupational therapy aides (Hettinger, 1995). Foto (1996) has called for the definition and delineation of which services require which staffing level secondary to maintaining quality of patient care and our professional expertise. Neither of these quality awareness initiatives, however, address how such changes have increased staff stress and lowered morale as noted by Grace (1995). 
Bridges (1989) noted the increased stress, resentment and anxiety which were shown to lower staff morale are typical signs of mismanaged transition management. Effective transition management foresees what will change, assesses the organization's transitional readiness, manages staff feelings of loss over ending current practices, and motivates staff to understand, accept and tap into the power of the actual change process before they are expected to launch into the new beginning and align themselves into their new roles.

Clearly, staffing mix changes hold more implications for the future of the occupational therapy profession than mere short term productivity and cost containment. The profession is tasked to how such changes will impact occupational therapy's role and reputation and decide what stance will favor the long term future of occupational therapy. Occupational therapy managers are tasked to resolve staff stress and morale issues which are obstructing the quality and process improvements of their departments. Occupational therapy initiative and leadership at the organizational level could restore feelings of control and purpose. As the drive for reengineering in health care continues, leadership initiatives are needed to clarify occupational therapy's core competencies in both individual practice settings and professional associations. Through the development of a clear pattem of identity and new sense of mission, transitions can be managed more successfully.

The occupational adaptation frame of reference could be used as a business strategy within the organization for both staffing and management issues. The occupational adaptation model emphasizes the creation of a therapeutic environment, the use of activity and the importance of relative mastery (Schultz \& Schkade, 1992). A therapeutic environment in an organization can be developed by an employee exchange of needs, visions and expectations. Implementing transition management in services could ready the employees for change. Employee participation in developing and implementing adaptation activities and definitions of success in those activities will round out the adaption process. Just as individuals need to integrate and generalize their learning to achieve mastery of new situations, so also do organizational groups. 
Quality of patient care under managed care is considered a sham by some who believe that cost control overshadows concem for clinical quality and patient satisfaction (Reinhardt, 1986; Wooley, S. C., 1993; Sharfstein, S.S., 1994; Wells, Astracham, Tischler, \& Unutzer, 1995). In response to complaints by consumer groups, several states have introduced legislation to mandate minimum levels of coverage and full disclosure of patient rights and coverage (Christiansen, 1996).

This study implies that timeliness of treatment and the value of provider expertise are aspects of quality care that may be compromised in the drive for cost control. In what other ways may we be inadvertently decreasing care quality as well as our value as a health professional? Clearly, managed care has challenged the occupational therapy profession to examine the looking glass for quality care practices, learn to express the value of those practices and actively advocate the role of the profession in patient care.

The results of this survey demonstrate the need to extend communication, trust, and team building beyond the walls of the separate organizations in order to provide a process that will provide cost effective quality patient care. Promoting success as everyone's role and insuring effective transition management are key components to quality process improvement efforts. Sata (1989) contends that system change and quality improvements are blocked unless all process participants share the same beliefs and are committed to take the actions necessary for change. Communication and team building are fundamental methods used by providers to improve quality and streamline costs (Higgins, 1995). Can our health care system under managed care evolve into a system of common purpose or is the quality of patient care destined to decline as health care is transformed from a social good to an economic good?

\section{Recommendations For Further Research}

As a result of this study a number of recommendations can be made for further research:

1. Investigate both successful and unsuccessful programs aimed at increasing morale for staff therapists in this changing environment 
2. Compare/contrast reimburser/provider communication patterns with quality of patient care.

3. Compare and contrast different organizational structures and processes with the effectiveness and quality of patient care.

4. Investigate the factors that would motivate or constrain occupational therapists from obtaining further education and training in managed care issues.

Further research from this study's qualitative section of the survey is also intended. The qualitative portion of the questionnaire allowed the managers to narratively discuss elements of their managed care experiences. Analysis of this research will be directed toward the development of responses to the following research questions:

A. What are the common themes from clinical patient stories in managed care reported by occupational therapy managers?

B. What are common occupational therapy manager role changes found in the managed care environment?

C. What learning events have been sought by both individual managers and organizations to better understand and adapt to managed care change?

D. Which learning events sought have been the most and least effective?

E. What initiatives have been taken at both organizational and personal levels in response to managed care changes?

These queries and research recommendations are aimed at issues that span across health care providers, managed care providers and clients within our health care environment. These recommendations seek an enhanced understanding of what exists, what is changing and what are the implications of those changes. An early task in transition management is to foresee what are the implications of the given changes for strategies, goals, structure, roles, values, beliefs, economics, and resources (Bridges, 1989). This knowledge is needed by rehabilitation managers to develop a well thought out transition management plan. Occupational therapy leadership is needed to research and voice solutions that will elicit positive transition within our changing health care system. 


\section{References}

Alvarado, D. (1995, April, 18). Doctors challenge limits on spending. San Jose Mercury News, pp. 1A, 6A.

Anders, G. \& Stout, H. (1994). With Congress stalled, health care is shaped by the private sector. The Wall Street Joumal, 131, pp.A1, A12.

Bailey, D. M. \& Schwartzberg, S.L. (1995). Ethical and legal dilemmas in occupational therapy. Philadelphia: F.A. Davis.

Bridges, W. (1989). Transition management: An introductory guide. Miil Valley, CA: Author.

Burcham, M.R. (1994, August/September). Strategic planning for managed care. Rehab Management, 7 (3), 93-99.

Burke, J.P. \& Cassidy, J.C. (1991). The issue is: Disparity between reimbursement-driven practice and humanistic values of occupational therapy. American Journal Of Occupational Therapy 45 (2), 173-176.

California Secretary of State. (1996). Califomia general election ballot pamphlet: November 5, 1996. Sacramento, CA: Author.

Christiansen, C. (1996). Managed care: Opportunities and challenges for occupational therapy in the emerging systems of the 21 st century. American Journal of Occupational Therapy, 50 (6), 409-412.

Clifton, D.W. \& Tecklin, J.S. (1995, January/February). Under the watchful eye. Rehab Management, 8 (1) $43-47$.

Coile, R.C. (1994, September). Strategic executive briefing: The five stages of managed care. Hospital Strategy Report, 6 (11), 4-8.

DePoy, E. \& Gitlin, L.N. (1994). Introduction to research: Multiple strategies for health and human services. St. Louis, MO: Mosby.

Diasio Serrett, K. \& Gomes, E. (1991). Assessment of the needs of occupational therapy managers for advanced management skills. Paper presented at AOTA conference. Cleveland, $\mathrm{OH}$. 
Diasio Serrett, K. \& Duncan, J. (1995). A qualitative study of the impact of managed health care on occupational therapy. Unpublished manuscript. San Jose State University, San Jose, CA.

Diasio Serrett, K. (1995). Managed care: A study of the impact on occupational therapy. California state university grant proposal. San Jose State University, San Jose, CA.

Egan, M. (1992, October 8). HMO Contracts: Partnerships for the future. OT Week, 14-15.

Ellek, D. (1990). The new direction in health policy. American Journal of Occupational Therapy. 44 (10), 947-949.

Ellek, D. (1995). Managed competition: Maintaining health care within the private sector. American Journal of Occupational Therapy 49 (5), 468-472.

Ellenberg, D.B. (1996). Outcomes research: The history, debate, and implications for the field of occupational therapy. American Joumal of Occupational Therapy, 50 (6), 435-441.

Fisher, R.S. (1994). Medicaid managed care: The next generation? Academic Medicine, 69, 317-322.

Fisher, T. (1996). Roles and functions of a case manager. American Journal of Occupational Therapy, 50 (6), 452-454.

Fleming, M.H. (1993). Aspects of clinical reasoning in occupational therapy. In H.L. Hopkins \& H.D. Smith (Eds.), Willard and Spackman's Occupational Therapy (8th ed., pp. 867-881. Philadelphia: J.P. Lippincott.

Foto, M.(1988a). Nationally speaking: Managing changes in reimbursement patterns, Part 1. American Journal of Occupational Therapy, 42 (9), 563-565.

Foto, M.(1996). Multiskilling: Who, how, when, and why? American Journal of Occupational Therapy, 50 (1), 7-9.

Fowler, F.J. \& Gill, H.S. (1994). Strategic Alliances: The approach to the future. Rehab Economics, 2, 82-83. 
Garrett, S.A. \& Schkade, J.K. (1995). Occupational adaptation model of professional development as applied to level II fieldwork. American Journal of Occupational Therapy, 49 (2) 1 119-126.

Gomes, E. (1991). Assessment of the needs of occupational therapy managers for advanced management skills. Unpublished master's thesis. San Jose State University, San Jose, CA.

Grace, A. (1995, February 16). Charting changes in rehab. OT Week, 16-17.

Hall, M.A. (1992). The political economics of health insurance reform. Health Affairs, 11 (2), 108-124.

Hettinger, J. (1995, September 28). A question of roles. OT Week, 18-19.

Hettinger, J. (1995, October 12). Training competent aides. OT Week, 18-19.

Hettinger, J. (1996, August 1). Case managers: Do OTs have what it takes? YES! OT Week, 12-14.

Hettinger, J. (1996, January 11). To: OTs From: Physiatrists Subject: Adjusting to managed care. OT Week, 18-19.

Hettinger J. \& Topper, R. (1995, November 2). ASHT president urges change. OT Week, 6-7.

Higgins, C. (1992, June 25). Quality is... OT Week, 14-15.

Howard, B.S. (1991). How high do we jump? The effect of reimbursement on occupational therapy. American Journal of Occupational Therapy, 45 (10), 875-881.

Joe, B.E. (1996, August 1). Managed care: Special needs focus. OT Week, 16-17.

Joe, B.E. \& Hettinger, J. (1995, July 27). Managed care: Another occupational challenge. OT Week, 18-20.

Koumoutzis, N. (1994, December). Make behavioral considerations your first priority in quality improvements. Industrial Engineering, pp.63-65.

Landry C. \& Knox, J. (1996). Managed care fundamentals: Implications for health care organizations and health care professionals. American Joumal of Occupational Therapy, 50 (6), 413-416. 
Lumsdon K. \& Haglund, M. (1993, October 20). Mapping care. Hospitals \& Health Networks, 34-40.

Madden, M.J. \& Ponte, P.R. (1994). Advanced practice roles in the managed care environment. Journal of Nursing Administration, 24, 56-62.

Marszalek-Gaucher E. \& Coffey, R. J. (1990).Transforming health care organizations: How to achieve and sustain organizational excellence. San Francisco: Jossey-Bass.

Miller, R.H. \& Luft, H.S. (1994). Managed care plan performance since 1980. Journal of the American Medical Association, 271, 1512-1519.

Miller, S.I. (1994). Drugs \& alcohol: The clinician's view. In R.K. Schreter, S.S. Sharfstein, \& C.A. Schreter (Eds.), Allies \& adversaries: The impact of managed care on mental health services. (pp. 135-157). Washington DC: American Psychiatric Press.

Nevis, E.C., DiBella, A.J. \& Gould, J.M. (1995). Understanding organizations as learning systems. Sloan Management Review, 36 (2), 73-85.

Olmos, D.R. (1994, December 16). HMO report card: Big contrast in cash spent on care. San Francisco Chronicle, A5.

Pew Health Professions Commission (1993). Health professions education for the future: Schools in service to the nation. San Francisco: Author.

Pontzer, K. (1996, April 4). AOTA lobbies for managed care standards. OT Week, 5.

Pontzer, K. (1994, November 17). Responding to managed care. OT Week, 3538.

Reinhardt, U.W. (1986, July/August). Quality of care in competitive markets. Business and Health, pp.7-9.

Salcido, R. (1995). Sorting and saving. Rehab Management, 8 (2), 32-38.

Sata, R. (1989). Organizational learning: The key is management innovation. Sloan Management Review, 30 (3), 63-74. 
Schkade, J.K. \& Schultz, S. (1992). Occupation adaptation: Toward a holistic approach for contemporary practice, part one. American Joumal of Occupational Therapy, 46 (9), 829-837.

Schkade, J.K. \& Schultz, S. (1992). Occupation adaptation: Toward a holistic approach for contemporary practice, part two. American Journal of Occupational Therapy, $\underline{46}(9), 917-925$.

Senge, P.M. (1990). The fifth discipline: The art \& practice of the learning organization. New York: Doubleday.

Sharfstein, S.S. (1994). Ethical issues under managed care: The clinician's view. In R.K. Schreter, S.S. Sharfstein, \& C.A. Schreter (Eds.), Allies \& adversaries: The impact of managed care on mental health services. Washington DC: American Psychiatric Press.

Sheldon, J. \& Craig, H.M. (1994, December 5). It takes more than players to make a team. OT Advance, 20-21.

Singer, D.W. (1994). Functional capacity assessment. Rehab Management, 7 (3), $107-112$.

Smith, B.C. \& Elberth, W. (1993, April 8). Managed care: The key to reimbursement in mental health. OT Week, 22-23.

Spicer, J.W. (1992). Quality management and clinical pathways. Strategies \& Solutions, 1, 21-24.

Sullivan, T. (1995). Crossing the rehab bridge. Rehab Management, 8 (1), 98-102.

Thiers, N. (1994, August 18). Facing foreign territory. OT Week 16-19.

Todd, M.K. (1993). Networking - IPA. PHO, \& MSO development strategies. Nashville, TN: Business Network.

Van Leit, B. (1996). Managed mental health care: Reflections in a time of turmoil. American Journal of Occupational Therapy, 50 (6), 428-434.

Vogel, L.L. (1996). Satisfaction measurement of rehabilitation services. Rehab Management, 9 (4), 68-70. 
Wells, K., Astrachan, B., Tischler, G. \& Unutzer, J. (1995). Issues and approaches in evaluating managed mental health care. Milbank Quarterly, 73, 57-76.

Wilkerson, D. (1995). Developing outcomes management tools. Rehab Management. 8 (1), 114-117.

Wilson, A.A. (1993). The cost and quality of patient outcomes: A look at managed competition. Nursing Administration Quarterly, 17 (4), 11-16.

Wooley, S. C. (1993). Managed care and mental health: The silencing of a profession. International Journal of Eating Disorders, 14 (4), 387-401. 


\section{Appendix A \\ Definitions}

Appropriate setting: Efficiency and efficacy of the treatment location. The push for appropriate settings has driven the health care industry to vertically integrate as it moves toward a continuum of care which shifts clients into less expensive settings as soon as possible (Fowler \& Gill, 1994).

Clinical pathway: Series of events that all patients with a particular diagnosis will encounter that, when well managed, result in a effective and efficient path to recovery for similar groups of people (Spicer, 1992).

Clients: Patients and/or families who receive occupational therapy services.

Leadership Role: Decision making position taken to proactively initiate change within an organization.

Managed Care: A system of health care provision that addresses patient needs through a spectrum of alliances in order to control the cost of, access to, and quality of health care (Todd, 1993).

Medical Necessity: Service or treatment that is consistent with the diagnosis, and which cannot be omitted without adversely affecting the member's condition or quality of care rendered (Burcham, 1994).

Occupational Therapy Managers: Those persons who have completed an occupational therapy curriculum accredited by the American Occupational Therapy Association, have successfully passed the examination necessary to become a registered occupational therapist (OTR), and are responsible for the operations of an occupational therapy treatment setting. Services Delivery: The planning, implementation, and management of occupational therapy treatment services for a given client population.

Utilization management: The review and evaluation of each patient's treatment in terms of medical necessity, appropriate setting, utilization frequency, and resource management (Burcham, 1994). 
Appendix B

Consenting Cover Letter for Participants 
April 1, 1996

\section{Dear Colleague:}

We would like to ask you for your time and participation in a research study to identify the impact of managed care and related health care changes on occupational therapy/rehabilitation practice, an area of urgent concern for the profession. Currently, there is little research that can assist us in shaping our contributions within the vastly changing health care arena.

This study, supported by California State University grants, asks you to respond to these general areas of inquiry:

- changes in clinical practice that are occurring

"current organizational changes underway where you practice

"current organizational learning strategies being pursued

- your recommendations for further leaming that needs to be offered to health professionals

"commentson the initiatives and innovations that you have taken and found effective

"a story on the effects of these changes on dients/patients.

Filling the questionnaire will take approximately $20-30$ minutes of your time. Results of the survey will produce urgentily needed information related to the shape of the problems directors or lead therapists are facng as well as straegies that can be used to effectively address the numerous issues brought about by the vast changes occurring in today's practice environments.

Please help us make this research represent your interests. Your participation and response will help to make this survey serve its ultimate purpose - the design and development of effective strategies and learning events to keep occupational therapy/rehabilitation viable in this changing environment. Your response to the questionnaire implies your consent to participate in the study, which is , of course, voluntary. All responses are confidential. We welcome any comments or inquiries regrading this research.

You may either use the enclosed envelope to return your survey or fax it to (408) 720-8248, which is a private home office where the information remains completely confidential. We would like a response by April 23, 1996. Results will be made available in professional conference presentations and in published format at some time in the near future.

Any questions or issues can be directed to Karen Diasio Serrett, Ph.D. OTR, FAOTA, professor of occupational therapy at (408) 730-1229 or Cindy Haut, OTS at (408) 924-3074. Karen Diasio Serrett is principal investigator and Cindy Haut is research collaborator and is completing her thesis for Master of Science in Occupational Therapy at San Jose State University. Further University -based resources for your concerns or for questions regarding research participants rights may be directed to Serens Stanford, Ph.D., Associate Vice President for Graduate Studies at (408) 924-2480.

Thank you in advance for your collaboration,

Karen Diasio Serrett, Ph.D. OTR, FAOTA Professor, Department of Occupational Therapy Principal Investigator
Cindy Haut, OTS (MS program SJSU)

Research Collaborator 
Appendix C

Questionnaire 
Thank you for filling out the following survey. Your participation is greaty appreciated.

\section{Backsround Information - Your Organization}

1. In the last 2 years, has your organization partnered with other organizations to provide a wider continuum of care?

$$
\text { Q Yes }
$$

No

2. How long have major restructuring changes occurred within your organization?
No major changes
L Less than 9 mos.
9 mos. -2 yrs.
Between 2 - 3 yrs.
Over 3 yrs.

3. Where are OT services offered within the continuum of care in your organization? (check all that apply)

$\square$ Home health

Skilled nursing facility

acute inpatient

$\checkmark$ Subacute inpatient

a Outpatient

Other (specify)

4. State in which you practice (specify)
5. What best describes your organization's status in relation to managed care?

Know it's coming but it has not yet directly affected clinical practice

- Actively involved in preparation for managed care - Implementing services changes due to managed care contracts

6. How long has this setting had managed care contracts? (nearest year or month)

7. To what extent have managed care contracts been an influence in these changes?

a None

S Some

Major

$\square$ Other (specify)

8. Type of organization

State

C County

Other non-profit organization

Contracting organization

D Private practice

Other for-profit organization

\section{Your Background and Current Practice Setting}

9. Highest degree received:

Baccalaureate degree

Master's degree

Q PhD

Other important credentials (specify)

10. Major area of practice in current setting (check up to two areas)

G Hand

Q Geriatrics

- Pediatrics

口 Physical Disabilities

Mental health/Behavioral health care

a Prevention \& Wellness

$\square$ Other (specify)

11. How are you involved in the managed care contract process? (check all that apply)

Not involved in managed care contracts

Negotiations

Q Reviewing contract terms

Implementing contract within work unit

o Other (specify)
12. Which of the following best characterizes your position?

Supervisor / lead therapist

Q Middle management

Upper management

Practicing owner/partner

13. Has your position changed significantly in the last 2 years?

$\square$ Yes

D No

14. Do you supervise disciplines other than OT?

a Yes

No

15. Have any of the following staffing changes occurred in last 2 years?

- Increase in Aides

a Decrease in Aides

a Increase in COTAs

a Decrease in COTAs

Increase in OTRs

Decrease in OTRs 


\section{Changes in Clinical Practice}

Please girde the scale number that best matches your perception of the following statement for each practice issue. Use the following scale 1-Strong increase, 2-Slight increase, 3 - Neutral, 4-Slight decrease, 5-Strong decrease, or NA.

16. For us to be competitive, the following have seen dramatic changes in the last 2 years:

$\begin{array}{lllllll}\text { a. Physical agent modalities } & 1 & 2 & 3 & 4 & 5 & \text { NA } \\ \text { b. Patients treated in groups } & 1 & 2 & 3 & 4 & 5 & \text { NA } \\ \text { c. Selection of personally meaningful dient activities } & 1 & 2 & 3 & 4 & 5 & \text { NAA } \\ \text { d. Transdisciplinary treatment evaluation and planning } & 1 & 2 & 3 & 4 & 5 & \text { NAA } \\ \text { e. Patient/ caregiver education efforts } & 1 & 2 & 3 & 4 & 5 & \text { NA } \\ \text { f. Case management } & 1 & 2 & 3 & 4 & 5 & \text { NA } \\ \text { g. Time spent by OTRs in direct client care } & 1 & 2 & 3 & 4 & 5 & \text { NA } \\ \text { h. Middle managers performing direct client care } & 1 & 2 & 3 & 4 & 5 & \text { NA } \\ \text { i. New program/ product line development } & 1 & 2 & 3 & 4 & 5 & \text { NA } \\ \text { j. Cost management planning and procedures } & 1 & 2 & 3 & 4 & 5 & \text { NA } \\ \text { k. OT services integrated across care continuum } & 1 & 2 & 3 & 4 & 5 & \text { N/A } \\ \text { l. Competency validation/credentialing efforts } & 1 & 2 & 3 & 4 & 5 & \text { N/A } \\ \text { m. Continuous quality improvement efforts } & 1 & 2 & 3 & 4 & 5 & \text { N/A } \\ \text { n. Time spent doing clerical/administrative tasks } & 1 & 2 & 3 & 4 & 5 & \text { N/A }\end{array}$

\section{Oreanizational Leaming}

Please gircie the scale item that best matches your perception of the following statements about your workplace . Use the following scale: 1-Strongly agree, 2- Agree, 3- Neutral, 4- Disagree, 5-Strongly Disagree, or NA.

Check the line if you would recommend further education for occupational therapists in this area.

17. We have been actively promoting activities such as health fairs, wellness and prevention workshops, support groups, and other community outreach efforts.

18. We take the time to make sure clients clearly understand their rehabilitation benefits and how these relate to their recovery.

19. Our partnerships with our managed care / third party payors have been mutually satisfactory.

20. A strong focus on our clients' satisfaction pervades all levels of staff.

21. Cinical staff have been coached in ways to develop new programs to better meet needs of targeted populations.
Recommend

more

Education?

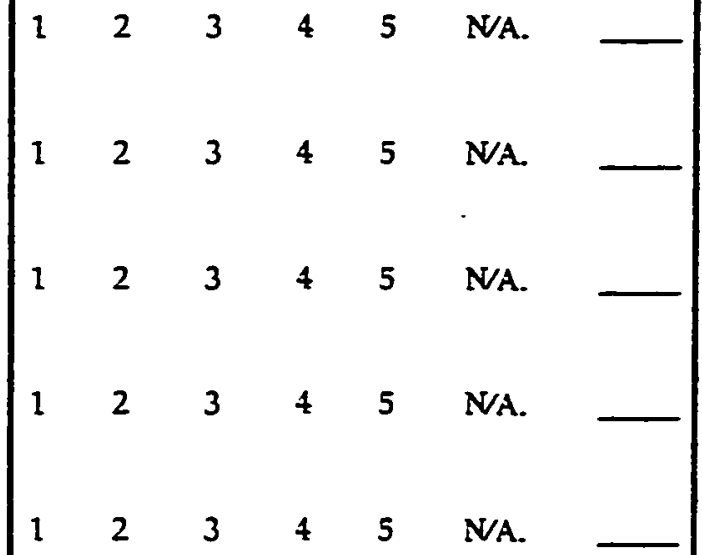


Please circle the scale item that best matches your perception of the following statements about your workplace.

22. We are actively involved in working with employers directly in determining health needs of their employees.

23. Timely client care has been hampered by managed care policies and procedures.

24. We have seen definite improvement in the quality of services to patients as a result of our change efforts.

25. A large gap exists between the care the patient expects and the care we can deliver under managed care coverage.

26. Cost containment has in fact outweighed other aspects of restructuring despite statements made about maintaining or enhancing quality.

27. Cinical staff spend significantly more nonreimbursed time talking with insurance companies or other entities to get authorization for client treatment.

28. Our organization rewards staff initiatives that lead to innovations in clinical services and work processes.

29. Clinical staff have not yet changed their perspectives to include understanding the what and why of organizational changes that are occurring.

30. Our current functional outcome measures are so general that they don't adequately measure OTs capacity for intervention.

31. Time and financial resources have been committed to support lifelong learning for clinical staff.

32. Cinicians are often put in ethical binds because of limitations in managed care contracts.

33. Many change efforts have been at cross purposes and have created confusion and wasted effort.

34. Managed care contracts have made our clinicians more accountable for efficient and effective client care.

35. We have computerized information to enhance our productivity with documentation and outcomes research.

36. Reimbursement/administrative policies have caused significant problems in implementing a continuum of care.
1-Strongly agree, 2- Agree, 3- Neutral, 4 Disagree, 5- Strongly Disagree, or NA.

\section{Recommend more Education?}

$\begin{array}{llllll}1 & 2 & 3 & 4 & 5 & \text { NA. } \\ 1 & 2 & 3 & 4 & 5 & \text { NA. }\end{array}$

1

$\begin{array}{lllll}2 & 3 & 4 & 5 & \text { NA. }\end{array}$

1

1

2

3

4

5

NA.

1

2

3

4

5

NA.

$\begin{array}{llllll}1 & 2 & 3 & 4 & 5 & \text { NA. }\end{array}$

1

2

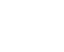

$\begin{array}{llllll}1 & 2 & 3 & 4 & 5 & \text { NA. }\end{array}$

$\begin{array}{llllll}1 & 2 & 3 & 4 & 5 & N A .\end{array}$

$\begin{array}{llllll}1 & 2 & 3 & 4 & 5 & N A\end{array}$

$\begin{array}{llllll}1 & 2 & 3 & 4 & 5 & \text { NA. }\end{array}$

$\begin{array}{llllll}1 & 2 & 3 & 4 & 5 & N A\end{array}$

$\begin{array}{llllll}1 & 2 & 3 & 4 & 5 & \text { NA. }\end{array}$ 
Please circle the scale item that best matches your perception of the following statements about your workplace.

37. Interdisciplinary dinical pathways have helped us better define our work processes.

38. Work requiring the team efforts of different clinical disciplines now gets done more smoothly.

39. We have created task forces to identify and eliminate underlying causes of work process problems.

40. Staff dedication to our organization's mission and vision helps us take pride in our service and staffing priorities.

41. We are frustrated by the limitations imposed on our professional expertise by managed care contracts.

42. Our organization has been giving clinical staff a better picture of health care trends and how those trends relate to services we need to provide.

43. Insurance case managers' lack of understanding of our health care role has resulted in loss of referrals for needed client care.

44. Cross disciplinary change efforts have been inclusive of all staff levels and professions.

45. We have worked on defining our unique strengths, and built on those, and let go of "being all things to all people."

46. This organization has been conscientious about paying attention to the human aspects of change for employees.

47. Advocacy for patients has resulted in warnings or reprimands from health care plan representatives.

48. Middle-level managers are informed and participate in decision-making about proposed clinical service changes.

49. There are many areas needing change in this system which are not being addressed by work on clinical pathways.

50. We frequently request client feedback on care quality and incorporate their priorities into our care process.

51. A strong level of trust and open dialogue is being developed between management and clinical staff.

52. Cinical staff rarely participates in gaining continuous quality improvement and work process redesign skills.
1-Strongly agree, 2- Agree, 3 - Neutral, 4 Disagree, 5- Strongly Disagree, or NA.

Recommend more

Eduation?

$\begin{array}{llllll}1 & 2 & 3 & 4 & 5 & N A\end{array}$

1

$\begin{array}{llllll}1 & 2 & 3 & 4 & 5 & \text { NA. }\end{array}$

$\begin{array}{llllll}1 & 2 & 3 & 4 & 5 & \text { NA }\end{array}$

$\begin{array}{llllll}1 & 2 & 3 & 4 & 5 & \text { NA. }\end{array}$

$\begin{array}{llllll}1 & 2 & 3 & 4 & 5 & \text { NA. }\end{array}$

$\begin{array}{llllll}1 & 2 & 3 & 4 & 5 & N A\end{array}$

$\begin{array}{llllll}1 & 2 & 3 & 4 & 5 & \text { NA. }\end{array}$

$\begin{array}{llllll}1 & 2 & 3 & 4 & 5 & \text { NA. }\end{array}$

$\begin{array}{llllll}1 & 2 & 3 & 4 & 5 & \text { NA. }\end{array}$

$\begin{array}{llllll}1 & 2 & 3 & 4 & 5 & \text { NA. }\end{array}$

$\begin{array}{llllll}1 & 2 & 3 & 4 & 5 & N A .\end{array}$

$\begin{array}{llllll}1 & 2 & 3 & 4 & 5 & \text { NA. }\end{array}$

$\begin{array}{llllll}1 & 2 & 3 & 4 & 5 & \text { NA. }\end{array}$

$\begin{array}{llllll}1 & 2 & 3 & 4 & 5 & \text { NA. }\end{array}$

$\begin{array}{llllll}1 & 2 & 3 & 4 & 5 & \text { NA. }\end{array}$ 


\section{Health Care Changess and You}

1. What is most different about your role since the advent of significant healthcare changes in your organization?

What was most personally demanding about this sole change?

2 What leaming events have helped you the most in making an effective transition to a managed care environment?

Sponsored by organization

My own self-directed leaming

3. What organizational leaming events were leasteffective in helping make a smooth and successful transition?

4. What initiatives /innovations have you have successfully developed in the areas of leadership, total quality management, and clinical practice to ensure quality occupational therapy services?

5. Can you share a clinical story about a patient who was either negatively or positively affected by managed care benefits? 